\title{
A Theory of Fair Employment Laws
}

\author{
Owen M. Fiss $\dagger$
}

Laws prohibiting racial discrimination in employment are now a familiar component of our legal system. There is, however, a growing uncertainty as to the limits of the obligation imposed by these laws, and this uncertainty often creates a dilemma for employers and enforcement agencies. Increased efforts to enforce or to comply are met with the claim that preferential treatment is being given to blacks and that such preferential treatment violates the law. On the other hand, decreased efforts are met with equally forceful protests that whites are receiving preferential treatment and that, too, violates the law.

The limits of any law are in large part determined by details of history and language. In these respects fair employment laws vary greatly. But central to all these laws is a common regulatory devicethe prohibition against discrimination. Fair employment laws regulate by prohibiting employers from discriminating on the basis of certain individual traits, such as race, religion, national origin, or sex, and by authorizing or establishing procedures or remedies to induce or coerce employers to comply with that prohibition. My concern is with this common regulatory device, the antidiscrimination prohibition, particullarly as it applies to race. I address myself, not to any single fair employment law, but to a simplified and abstract version that simply commands employers not to discriminate against any person on the basis of his race or color. Analysis of this prototype will not set the limits of any single fair employment law; but it may identify the underlying theory of laws prohibiting racial discrimination in employment, and that seems to be the first step in understanding the limits of the obligation imposed by such laws.

In analyzing prohibitions against racial discrimination, one aphorism constantly recurs-that of color blindness. Its genesis can be traced to the dissent of Justice Harlan in Plessey v. Ferguson. ${ }^{1}$ Since then, the aphorism has played a dominant role in the interpretation of antidiscrimination prohibitions, regardless of the activity covered, whether

† Associate Professor of Law, The University of Chicago.

1 163 U.S. 537, 559 (1896). 
it be public education, jury selection, voting, housing, public accommodations, or employment. Quite apart from what Justice Harlan intended, the message conveyed by the metaphor is that the essence of the obligation not to discriminate is for the pertinent decision-maker not to take color or race-any color or race-into consideration. The effect of blindness is to treat all colors as normative equivalents, and thus the metaphor is particularly handy in expressing an opposition to increased enforcement on the ground that such enforcement will result in preferential treatment for blacks.

In some areas, such as education and voting, ${ }^{2}$ there is a growing recognition that in some instances it is consistent with the antidiscrimination prohibition to take race into consideration. Indeed, some fairly well-established doctrine concerning antidiscrimination prohibitions forbids that race be ignored. Although there is considerably less experience in construing the antidiscrimination prohibition of fair employment laws, the available doctrine and enforcement experience suggest that in the employment context too the emerging vision of the law is conscious of color. There are limits to that vision, and I believe it important to identify them. But these limits are complex and subtle, and the limits in employment differ from those in other areas of human activity. The norm of color blindness ignores this, and thus in my judgment provides little understanding of the legal obligation imposed by fair employment laws.

\section{The Theory of Fair Employment Laws AND THE NORM OF COLOR BLINDNESS}

Fair employment laws confer benefits upon a class of persons, namely, the actual and likely victims of discrimination. In the case of the prohibition against racial discrimination, that class consists predominantly of Negroes. At least on the federal level, enactment was largely a response to patterns of discrimination against Negroes; the resources of public enforcement agencies have been committed primarily to inducing or coercing employers not to discriminate against Negroes; and Negroes were intended to be and, I would venture to guess, have turned out to be the primary and immediate beneficiaries of the prohibition against racial discrimination.

2 Elsewhere I have addressed similar issues relating to the assignment of students among public schools, Racial Imbalance in the Public Schools: The Constitutional Concepts, 78 HARv. L. REv. 564 (1965), and to voting qualifications, Gaston County v. United States: The Fruition of the Freezing Principle, 1969 Sup. CT. REv. 379. Although I will draw heavily on the analyses in those articles, my approach is premised on the view that the antidiscrimination prohibition has different contours as it applies to different areas of human activity. 
The supporters of fair employment laws are not unrealistic about the race of the class upon whom the law confers its direct benefits. It is black. But the desire to help blacks is qualified. It is qualified, first, by a recognition that discrimination against Negroes violates certain principles that attach no particular importance to which color happens to be the basis of the employment decision. Thus the prohibition is couched in terms of "race" or "color"-without specifying which race or color." Second, the law contemplates conferring only a limited benefit. It does no more than prohibit businessmen from making employment decisions on the basis of race or color-a criterion whose use would in any event impair rather than advance productivity and wealth maximization for the individual businessman and for society as a whole. These two qualifications make the conferral of benefits on blacks particularly palatable, ethically and politically, to the political majority. It is from these qualifications that the norm of color blindness emerges.

\section{A. The Aims of the Law: Securing Equality for Negroes}

Laws prohibiting racial discrimination in employment are inextricably linked to the goal of securing for Negroes a position of "equality." There are, however, two senses to "equality" in this context. One is equal treatment. Individual Negroes should be treated "equally" by employers in the sense that their race should be "ignored," that is, not held against them. This sense of equality focuses on the starting positions in a race: If color is not a criterion for employment, blacks will be on equal footing with whites. The second sense of equality"equal achievement"-looks to the outcome of the race. It relates to the actual distribution of jobs among racial classes and is concerned with both the quantity and the quality (measured, for example, by pay level

3 The assumption is that the legal prohibition of the fair employment law reads: It is unlawful to discriminate against an individual because of his race or color. This is quite different from a prohibition that reads: It is unlawful to discriminate against a Negro because of his race or color. It should be noted, however, that 42 U.S.C. $\$ 1981$ (1964), derived from the Civil Rights Act of 1866, is close to the latter pattern. It reads:

All persons within the jurisdiction of the United States shall have the same right in every State and Territory to make and enforce contracts, to sue, be parties, give evidence, and to the full and equal benefit of all laws and proceedings for the security of persons and property as is enjoyed by white citizens, and shall be subject to like punishment, pains, penalties, taxes, licenses, and exactions of every kind, and to no other.

Following the Supreme Court construction in Jones v. Alfred H. Mayer Go., 392 U.S. 409 (1968), of 42 U.S.C. $\$ 1982$ (1964), another law derived from the Givil Rights Act of 1866, $\S 1981$ has recently been construed by lower federal courts to prohibit racial discrimination by private employers. Waters v. Wisconsin Steel Works of Int'1 Harvester Co., 427 F.2d 476 (7th Cir. 1970); Sanders v. Dobb Houses, Inc., 63 CCH Lab. Cas. If 9511 (5th Cir. 1970); Copeland v. Mead Corp., 3 CCH Empl. Prac. Dec. If 8058 (N.D. Ga. 1970); see Comment, Racial Discrimination in Employment Under the Civil Rights Act of 1866, 36 U. CHI. L. Rev. 614 (1969). 
and social status) of the jobs. Jobs should be distributed so that the relative economic position of Negroes-as a class-is improved, so that the economic position of Negroes is approximately equal to that of whites. Disproportionate unemployment and underemployment of blacks should be eliminated or substantially reduced. ${ }^{4}$

These two senses of equality are linked in fair employment laws, but it is not clear which is the goal of the law. Under one interpretation, the aim of a fair employment law is to secure equal treatment, and although equal treatment might alter the actual distribution of jobs and lead to equal achievement, such a result would be only incidental. Under an alternative interpretation, the aim is equal achievement, and the guarantee of equal treatment-the antidiscrimination prohibition-is the chosen method for equalizing the distribution of jobs among racial classes.

The distinction between these two views of the aim of the law is of little moment if it can be assumed that equal treatment will lead to equal achievement. But the assumption may be incorrect. It is conceivable, and indeed likely, that even if color is not given any weight in employment decisions, and in that sense equal treatment obtained, substantial inequalities by race in the distribution of jobs will persist in the immediate and foreseeable future.

Persistent inequalities in job distribution may be atributable to factors unrelated to particular employment decisions (that is, the conduct regulated by fair employment laws). For example, at any one point in time unemployment rates differ from industry to industry, from region to region, and from employer to employer; and disproportionate unemployment of blacks may be due to a heavy concentration of blacks in the industry, region, or business enterprise that has at any one moment the greatest unemployment. This unequal distribution may be due to custom, individual preference, or actual or imagined discrimination in areas other than employment, such as housing. ${ }^{5}$ It may simply be due to the fact that for blacks the starting point in the labor market was in the South and in agriculture. The concentration of blacks in nongrowth

4 For a review of recent statistics indicating disproportionate unemployment and underemployment rates by race, and the variations in these rates over time, from city to city, from industry to industry, and on the basis of sex and age, see Cassell, Chicago 1960-1970: One Small Step Forward, 9 Industrial Relations 277 (1970); Hiestand, Equal Employment in New York City, 9 Industrial Relations 294 (1970); Marshall \& Van Adams, Negro Employment in Memphis, 9 Industrial Relations 308 (1970); Doeringer \& Piore, Equal Employment Opportunity in Boston, 9 Industrial Relations 324 (1970); Schmidt, Los Angeles: Show, Little Substance, 9 InDustrial REIATIons 340 (1970).

5 See, e.g., Kain, Housing Segregation, Negro Employment and Metropolitan Decentral. ization, 82 Q.J. EcoN. 175 (1968); Mooney, Housing Segregation, Negro Employment and Metropolitan Decentralization: An Alternative Perspective, 83 Q.J. EcoN. 299 (1969). 
industries and regions, or business enterprises, may be corrected over time as the unemployed relocate themselves; but that takes time, and whites will also be relocating.

Inequalities in the actual distribution of jobs between the races might also be due to the decisions of individual employers-the subject regulated by fair employment laws. One need not resurrect any notions of "innate inferiority" to explain this possibility. One need only be realistic about the historical legacy of blacks in America-one century of slavery and another of Jim Crowism. This legacy may result in inequalities in the actual distribution of jobs in several ways.

First, even if race is not used by an employer, his decisions may be based on criteria that do not seem conducive to productivity and that, because of the legacy, give whites an edge. In an industrial system where whites have a preexisting edge, rules that prefer relatives of the existing work force (nepotism) or those who started working for the firm at an earlier point in time (seniority) are examples of such criteria. The colorblind version of fair employment laws emphasizes the negative proposition that race is not a permissible basis for allocating jobs, but it does not purport affirmatively to catalog the permissible criteria, requiring that they all be conducive to productivity.

Second, even if the employer does not use race and uses criteria apparently conducive to productivity in his employment decisions, the historic legacy may have left blacks with several types of disabilities. One disability might be motivational. Conceivably, this legacy of slavery and discrimination has been responsible for the lessening of motivation of the class, making its members less willing to compete aggressively for the opportunities that are open or less willing to submit to industrial discipline. The legacy may have also made it more difficult for Negroes to acquire the references necessary to evaluate future promise. Finally, the legacy may have left the class without the qualities, abilities, skills or experience that efficiency-oriented employment criteria demand. This impact of the legacy need not be confined to the older members of the class. For younger blacks, not directly exposed to slavery or Jim Crowism, the disabilities might be "inheritable." ${ }^{\text {The disabilities may }}$ have affected family structure, which in turn has an impact on a child's aspirations and on the guidance available. The disabilities also may have affected family wealth, which has an impact on the child's ability to acquire the training or credentials necessary to compete more successfully.

Thus the distinction between the two views of equality is real. The

6 See generally Duncan, Inheritance of Poverty or Inheritance of Race?, in ON UNDERSTANDING POVERTY 85 ( D. Moynihan ed. 1969). 
question that has to be asked is whether the goal of the antidiscrimination prohibition is equal treatment or equal achievement, and a great deal may turn on the answer to that question. For the equal treatment goal will constitute one, though only one, of the pressures to depart from the norm of color blindness. If equal achievement is the goal of the law, and, as may be the case, it is not obtained by color blindness, the desire to improve the relative economic position of blacks will create a greater temptation to construe the legal obligation arising from the command not to base employment decisions on race in a more and more "generous" fashion.7 There will be considerable pressure to construe the central regulatory device in a manner that would bring the law closer to the attainment of the alleged goal of equalizing the actual distribution of employment opportunities, and such a construction might well entail giving preferential treatment to blacks. On the other hand, the equal-treatment goal is more compatible with color blindness; it means that blacks are treated the same as whites and thus would seem to be achieved once all employment decisions are independent of the colors of the prospective employees.

The choice between these views of the aims of the law may be dictated by the language or history of the particular fair employment law in question. However, more likely than not, the relevant language or history, if any, will not be decisive. The choice will then reflect primarily what the decision-maker believes the goal of the law ought to be, and that in turn should depend, not on the decision-maker's self-interest, but on the ethical foundations of these goals.

1. The Equal-Treatment Concept: Responding to a Particularized Wrong. An employment decision is analyzable primarily as a decision to allocate a scarce opportunity-a job. The paradigm situation is one in which several individuals are competing for a limited number of

7 See, e.g., Blumrosen, The Duty of Fair Recruitment Under the Civil Rights Act of 1964, 22 Rutcers L. REv. 465, 466 (1968) ("The law will be deemed successful only when the unemployment rate for minorities comes more into line with the unemployment rates of the rest of the community. The elimination of minority differentials in unemployment rates will be a true signal that equal employment opportunity does in fact exist."); Cooper \& Sobol, Seniority and Testing Under Fair Employment Laws: A General Approach to Objective Criteria of Hiring and Promotion, 82 Harv. L. REv. 1598, 1670 (1969) ("This shift away from a restrictive focus on the state of mind of the employer is essential to the effective enforcement of fair employment laws, not merely because specific intent is difficult to prove, but because there is frequently no discriminatory intent underlying the adoption of seniority and testing practices, or a wide variety of other objective and apparently neutral conditions to hire and promotion. These conditions are possibly the most important contemporary obstacles to the employment and promotion of qualified black workers."). See also Comment, Title VII of the Civil Rights Act of 1964 and Minority Group Entry into the Building Trade Unions, 37 U. CFI. L. REv. 328 (1970). See pp. 289, 300 infra. 
opportunities. A choice among these individuals is required, and the question arises as to the appropriate criteria for that choice. A choice made on the basis of an improper criterion-classified by the law as "invidious" or "arbitrary"-is viewed as a particularized wrong. The rejected individual is not being treated fairly.

Two attributes of the racial criterion account for the sense of unfairness engendered by its use as the basis of an employment decision. The first is that an individual's race is not considered an accurate predictor of his productivity. Fair employment laws reflect a rejection of any views of innate inferiority and also a commitment to the principle that the choice among individuals for scarce opportunities should be on the basis of the individual's merit. ${ }^{8}$ In the employment context this commitment to the merit principle means that the individual businessman is expected to choose the most productive individual, that is, the best worker at any given wage rate. ${ }^{9}$ This will tend to maximize the businessman's own wealth, and it will foster society's interest in efficiency-producing the greatest number of goods and services at the lowest cost.

The second attribute is the absence of individual control. To judge an individual on the basis of his race is to judge him on the basis of his membership in a class where that membership is truly predetermined. Fair employment laws reflect not only a commitment to the merit principle but also a commitment to the principle that it is desirable to judge individuals on the basis of criteria that are within his reach. Each individual should, at least at some point in his life, have the power or capacity to put himself in the position of satisfying the criterion. Individual control is a value because it provides the prospect for upward mobility, an important incentive to self-improvement and efficient performance. Further, it is valuable because it rationalizes, and thus makes more tolerable, the unequal distribution of status and wealth among people in the society: failure is the individual's own fault. ${ }^{10}$ The principle that the individual should control his own fate also assumes that the allocation of scarce employment opportunities represents, to some extent, a reward. The reward may serve an instrumental purpose; it may be an incentive to develop the necessary qualities or skills or to perform well. Or the reward or allocation may be, for the individual, an end in itself. In either event, responsibility is a necessary condition for

8 See generally R. LANe, Polrtical Ideology (1962).

9 For an analysis of those employment decisions that are based on race and may nonetheless be conducive to greater productivity, see pp. 257.63 infra.

10 See generally Schaar, Equality of Opportunity and Beyond, in IX Nomos $228 \mathrm{~J}$. Pennock \& J. Chapman eds. 1967). 
being rewarded, and individual control is a necessary condition for responsibility.

In identifying these two attributes of race-unrelatedness to productivity and the absence of individual control-I do not mean to suggest that either attribute by itself would be sufficient to generate unfairness. For example, there may be nothing unfair about making promotion or layoff decisions purely on the basis of seniority, though such decisions may be inefficient. Similarly, there may be no unfairness in refusing to hire an individual because of a physical deformity that is related to productivity, even though that deformity is congenital or the result of a vicious attack by another. Instead, the suggestion is that both these attributes, unrelatedness to productivity and the absence of individual control, are inherent in race, and that together they account for the unfairness. ${ }^{11}$ The fact that both attributes coalesce in race should not, however, obscure the difference between the lack of individual control inherent in race and that involved in a deformity that is congenital or the result of a physical attack. Concepts such as "accident of birth," "bad luck," "misfortune," are often used to explain the presence of such a deformity, suggesting that although the trait is not within the individual's control, it is in some sense a matter of chance. But this ele-

11 Criteria other than race may, of course, be both unrelated to productivity and beyond individual control. When these criteria are used as a basis for allocating a scarce employment opportunity, unfair treatment or a particularized wrong occurs in much the same way as when race is used. Some of these criteria, such as sex and national origin, are frequently included in the reach of fair employment laws; others, such as eye color, are not. The selection among this universe of allegedly arbitrary criteria for inclusion within the reach of the fair employment laws depends on various factors: the size and power of the victim group within the total constituency; political strategies; some estimation as to whether conduct based on those criteria is sufficiently widespread and so firmly rooted as to warrant coercive intervention by the law; differences in the degree of unfairness; and, whether interfering with conduct based on these criteria would also serve other permissible purposes. The usual absence of some of these arbitrary criteria, such as eye color, from the reach of the fair employment laws may be due simply to these factors. One cannot argue from their absence that there is no unfairness in using race as a basis of allocating an employment opportunity, and that the aim of the prohibition against racial discrimination is not to express legal disapproval of the unfair treatment inherent in judging an individual on the basis of his race and to provide sanctions and remedies to respond to such particularized wrongs. Compare Winter, Improving the Economic Status of Negroes Through Laws Against Discrimination: A Reply to Professor Sovern, 34 U. Cri. L. REv. 817, 819-20 (1967). It might also be noted that, while Title VII of the Civil Rights Act of 1964 prohibits discrimination on the basis of religion, sex and national origin as well as discrimination based on race, it permits religion, sex or national origin to be used as a criterion for employment "where religion, sex, or national origin is a bona fide occupational qualification reasonably necessary to the normal operation of that particular business or enterprise." $\& 703(3)(1), 42$ U.S.C. $\$ 2000 \mathrm{e}-2(\mathrm{e})(1)$ (1964). Race is quite noticeably omitted from this exception and thus Congress seems to be reflecting a view that race-in contrast to these other traits-can never or very rarely be thought of as a "bona fide occupational qualification." 
ment of chance is not present with race; a child's race is not an accident or a matter of luck. It is not an aberration. A child's race is not only beyond his control but, perhaps more importantly, totally predictable. And it is perhaps this characteristic of race that has the most deadening impact on the prospect of upward mobility-one of the central values served by the principle that deems it desirable that an individual control his own fate. Members of the disfavored race must contemplate an inferior position, not only for themselves, but for their children, their children's children, and indefinitely on into the future.

Because of these attributes-unrelated to productivity and beyond individual control-allocating an employment opportunity on the basis of race constitutes a particularized wrong. There may, of course, be adverse practical consequences that flow from the conduct that gives rise to the wrong. To be denied a job may lessen income; it may frustrate a strong personal desire to get that job, to pursue a particular career, and to work with certain people; or it may cause an adverse psychological or emotional reaction. But it is important to distinguish between the particularized wrong inherent in denying a person a job on the basis of his race and the practical consequences that flow from that conduct. The particularized wrong-the unfair treatment-exists independently of these consequences to the individual, and is perceived without regard to an actual measurement of the consequences. It arises from the attributes of race, not from the consequences to the individual. It is this reason, and not just the lack of a feasible alternative, that, in my judgment, accounts for the fact that the antidiscrimination prohibition is so constructed that a violation of it does not depend upon an assessment of the actual consequences to the individual victim of the unfair treatment.

Nor does the violation of the antidiscrimination prohibition turn on whether the particular employment decision in question results in adverse consequences to society (for example, a decrease in overall productivity or social mobility). This may simply be a function of feasibility; a contrary view would probably create great uncertainties in enforcement and result in a rule that would be a most uncertain guide to those employers wishing to comply voluntarily. But I think that the structure of the prohibition is also a function of the fact that the unfairness of any particular employment decision based on race exists without regard to the consequences of that decision to society. The unfairness of using race as a basis for allocating jobs may be derived from certain ethical principles, such as the merit principle or the principle of individual control, which we in turn consider generally beneficial to society. But a distinction must be made between, on the one hand, justifying certain 
ethical principles and, on the other hand, recognizing particularized conduct inconsistent with those principles to be wrongful. ${ }^{22}$ The ethical principles in question may be ultimately justified by a utilitarian assessment of their overall beneficial role in society or on the view that they are among those few principles upon which universal assent can be imagined. However, once justified, they take on a life of their own, quite apart from their so-called ultimate justification, and particularized conduct inconsistent with them is perceived as "wrongful." The wrongful quality of the particularized conduct exists without in each instance relating the conduct to the so-called ultimate justifications, that is, without a judgment as to the utilitarian consequences of that particularized conduct to society as a whole and without in each instance imagining the outcome of taking a universal poll on the correctness of the particularized conduct.

2. The Equal-Achievement Concept: The Improvement of the Relative Economic Position of Negroes. The ethical basis for a law seeking equal treatment seems clear: Under the view that race is an arbitrary criterion, unequal treatment-disadvantaging Negroes because of their color-is one form of unfair treatment, a particularized wrong. However, the ethical basis for equal achievement-as an independent and distinctive goal of the law, and not merely as a possible incidental consequence of equal treatment-seems more uncertain to me. This uneasiness stems primarily from the redistributive quality of the equalachievement goal. This goal not only entails an improvement in the position of Negroes from what it is now but also an improvement in comparison to that of other groups. "Equality" is a relative concept; it involves a comparison. Since whites are the economically dominant racial group, a concern with equal achievement is basically a concern with the relative economic position of Negroes as compared to whites. Moreover, because of scarcity, the achievement of one group will be at the expense of the other. There is a symmetry to each achievement: what one group gets, the other does not. Even assuming an expanding economic pie, the improvement of the relative position of Negroes means that they get a larger slice of the increment, that Negroes are benefited more from the expansion than whites..$^{13}$ The redistributive aspect of this

12 See Rawls, Two Concepts of Rules, in 1955 PhiLosophical Rev. 64. See also Rawls, Justice as Fairness, in Justice ANd SOcIal Policy 80 (F. Olafson ed. 1961); Rawls, Distributive Justice, in Philosophy, Politics, AND Society 58 (P. Laslett \& W.G. Runciman eds. 1967); Rawls, Distributive Justice: Some Addenda, in 13 Naturat L.F. 51 (1968). Rawls' conception of justice is premised on a view that everyone or nearly everyone is risk averse; but I fail to perceive the basis for that premise.

13 It has been maintained that an expanding economy would increase the demand for labor, and that would improve the relative position of Negroes. See Anderson, Trickling Down: The Relationship Between Economic Growth and the Extent of Poverty 
goal is even clearer assuming a static pie. And since neither the legal obligation nor the enforcement of fair employment laws is conditioned upon increasing demand for labor, due account must be taken of the situation where the pie is static. The ethical questions posed by the equalachievement goal then are twofold. Why should society seek to obtain for Negroes a larger slice of the pie? How large should that slice be? There are several possible answers to these questions. Yet each is to some extent unsatisfactory.

a. Self-interest of blacks. An explanation couched in terms of the self-interest of blacks is inadequate. As a factual matter, the redistributive goal may indeed be a function of the class' self-interest and the class' political power, derived from its numbers and its ability to inflict costs (for example, street crime, urban riots) on an otherwise unresponsive society. But this self-interest of the class obviously does not provide a normatively adequate basis for enactment of a law or a guide for interpretation and enforcement of it. There would be no ethical basis for distinguishing the self-interest of this particular group (blacks) from that of any other group (for example, whites, Protestants).

b. Redistribution from the rich to the poor. An approach that seeks to justify the redistribution in the same terms as one that would justify redistribution of wealth from the "rich" to the "poor"14 seems to be of little significance here. For the redistribution in favor of blacks is not likely to be at the expense of the "wealthy." The jobs held by the "wealthy" are not likely to be the ones that Negroes, as a class, are competing for now; a few Negroes may be competing for those jobs, but their economic position is probably atypical of the class and not easily classified as "poor." The competitors for the same positions are likely to be in the same economic class; a higher proportion of blacks than whites can be classified as "poor," but blacks constitute a smaller portion than whites of those persons who can be classified as "poor."

Among American Families, 78 Q.J. EcoN. 511, 512 (1964); Tobin, On Improving the Economic Status of the Negro, 94 DaEdalus 878 (1965). The theory is that an increase in demand for labor will benefit those standing at the end of the hiring queue. But I do not understand why the increase in demand for labor will necessarily benefit those at the end of the queue more than those at the front. Those standing at the front of the queue are not stationary; they are likely to move into the higher-paying, more attractive jobs (get the benefit of the growth) and leave the lower-paying, less attractive jobs (that are not eliminated) to those at the end of the queue. If this occurs in a period of expansion, the relative position of whites and Negroes will not be materially altered by the expansion. There is some empirical evidence to suggest that that is what occurred during the 1960 's. Doeringer \& Piore, supra note 4, at 329, 335-36, 338-39; Marshall \& Van Adams, supra note 4, at 317-18.

14 For the identification and analysis of those principles, see W. BLUM \& H. KaIVEN, Jr., The Uneasy Case for Progressive Taxation (1963). 
The equal-achievement aim calls for a justification of a redistributive program on behalf of a racial, rather than an economic, class.

c. Efficiency. Considerations of efficiency do not seem to justify a redistribution in favor of blacks, or any racial class. One societal assumption, evidenced by fair employment laws, is that race is not a predictor of productivity. That assumption would apply equally if the redistribution were in favor of black (rather than white). A redistribution program in favor of blacks may be consistent with considerations of efficiency and greater productivity under certain limited conditions (that is, when the program does no more than prohibit employers from judging blacks on the basis of criteria, such as nepotism, that (a) are likely to minimize the blacks' share of the job market and (b) are not related in any significant way to productivity). Efficiency may not be sacrificed if that redistribution occurs. But the question still remains: Why should it occur?

d. Furtherance of certain social objectives. Redistributing jobs in favor of blacks may be looked on not as an end in itself but rather as a means of achieving other societal objectives. Whether redistribution can be justified in such instrumental terms depends upon the contribution redistribution will make toward the achievement of an objective, the availability of more effective alternative means for achieving the objective, and the importance of achieving that social objective when compared to the costs, economic or ethical, of redistribution.

(i) Maintenance of public order. The improvement of the relative economic position of the racial class may be necessary to maintain public order. This assertion assumes that blacks, as a class, believe that they should get a larger slice of the pie and that they attach sufficient importance to this aim to risk achieving it through unlawful activity, ranging from ordinary street crime to riots. Obviously, society has an interest in preserving peace, and it may decide that, even with continued use of the criminal laws, peace cannot be maintained unless the relative economic position of blacks is improved. But this merely shows that in some situations it may be expedient to redistribute to a racial class, not that it is right. And even the expediency of redistribution in these circumstances may be doubted because it invites all other classes to engage in similar conduct for furthering their selfish claims. This particular social objective-maintenance of public order-provides no basis for differentiating between these assertions of self-interest. It is not sufficient that the class feels its claim is "just."

(ii) Integration. To some extent, society seems committed to the goal of integrating public education on the theory that racially segregated education is either educationally undesirable or constitutes 
a denial of equal protection of the laws. ${ }^{15}$ Because there are certain values in drawing attendance boundaries on the basis of geographic criteria, racial segregation in residential patterns will limit the capacity of school boards to achieve integration. For this reason, and perhaps others, society has an interest in insuring that the relative economic position of blacks is improved so that a significant number of them will have the financial means to move into white residential areas and out of the ghetto. That this may be a justification for redistribution cannot be completely denied, but its significance is far from clear. Two questions are crucial: (1) Is the goal of integration so important that society is willing to effect a redistribution greater than would occur if employment decisions were not based on race? (2) Can it be fairly assumed that an increase in the relative economic position of Negroes will result in a significant increase in residential integration? These questions cannot be answered by a simple "yes/no." But the answers to both questions must tend toward the affirmative before an independent role for the redistributive goal can be predicted on its relation to integration; and the evidence for an affirmative answer to at least the second question seems sparse. There are many other factors besides inequalities in wealth that are responsible for ghettoization, and these will persist even if redistribution lessens the inequalities.

(iii) Black self-esteem. The concern with actual distribution of jobs also may be rooted in a concern with the image that blacks are thought to have of themselves if, regardless of the reason, all the "important," "prestigious" or "responsible" jobs are held by whites, or if, regardless of the reason, a disproportionate number of blacks are unsuccessful in their competition for the desirable jobs. Under this view it is thought important to society for blacks to see members of their class in highranking jobs, and thus develop self-confidence and pride, which might in turn have beneficial social consequences. At best, the force of this approach seems limited. The alleged beneficial social consequences flowing from this increased self-esteem are quite indeterminate. The approach calls for redistribution primarily in a limited range of jobs, one far narrower than those covered by the fair employment laws. It is addressed to the highly visible and highly prestigious jobs. Finally, if it is understood or even assumed that the redistribution occurred to a greater extent than if race were not held against Negroes, doubt would

15 For an analysis of the alleged value of integrating public education see Fiss, Racial Imbalance in the Public Schools: The Constitutional Concepts, supra note 2, at 567-70; U.S. Office of Educ., DeP'T of Health, Educ., \& Welfare, Equality of Educational OpPoRTUNITY (1966) (Coleman Report).

16 See Kain \& Persky, Alternatives to the Gilded Ghetto, in The Public INTERESr (Winter 1969). 
be cast on the value of the achievement. This is particularly true if redistribution were pushed beyond the point to which merit criteria would lead. There would be no confidence that the black got the high-status or better job because he was, in a merit sense, "better" than competing whites.

e. Responsibility for the inferior economic position. The last reason that might justify giving blacks a larger slice of the pie may reflect collective responsibility. The legacy of the class-as slaves and as victims of serious discrimination in all phases of life-in large part absolves the class of responsibility for its inferior position and fixes responsibility for that inferior position on society. Societal responsibility derives not only from widespread individual participation in the practices and institutions that kept blacks in an inferior position (slavery, Jim Crowism) but also from the impact of public laws and government agencies. Individual action conferring benefits on behalf of someone may be prompted and justified by recognition of responsibility for the helped individual's plight. And the suggestion is that society's action-the fair employment law-can be justified on the basis of a recognition of responsibility for the inferior economic position of Negroes. In large measure, I think, the redistributive goal is rooted in these sentiments. ${ }^{17}$

These sentiments are not transcendental. No sentiment is. Even if the acknowledgment of collective responsibility may justify a redistributive goal, it is still unclear how far the law is willing to pursue this goal. In general terms, the pursuit of this redistributive goal will be moderated by three factors. The first is society's willingness to impose sacrifices on itself (decreases in total wealth) or on particular individuals (competing white employees or individual businessmen). An unlimited pursuit of this redistributive goal can, of course, interfere with society's pursuit of other goals; indeed, it may so impair incentives for self-improvement as to undermine the productive system. Second, I believe that the pursuit of this redistributive goal will be moderated by a loss of confidence in the legacy theory as one necessarily moves from aggregate class concepts ("Negroes," "society") to individual concepts ("Negro applicant for a job," "individual employer"). Even though Negroes as a class may not be responsible for their inferior eco-

17 Immediately following the Civil War these sentiments perhaps were reflected in the establishment of the Freedmen's Bureau and proposals to give (on a time basis) the newly freed slaves 40 acres of land. Cox, The Promise of Land for the Freedmen, 45 Miss. Valley Hist. Rev. 413 (1959); G. Bentley, A History of the Freedmen's Bureau (1955). E. Rozwenc \& T. Lyons, Reconstruction and the Rage Problem (1968). The establishment of the Indian Claims Commission in 1946, 25 U.S.C. $\$ 70$ (1964), primarily to deal with land claims, and, of course, the reparations system in Germany following World War II reflect similar concerns. See generally Hughes, Reparations for Blacks?, 43 N.Y.U.L. REV. 1063 (1968). 
nomic position, perhaps there were things this particular Negro could have done to put himself in a better competitive position. Or, even though society may be responsible for imposing disabilities on blacks and thereby impairing their competitive position, perhaps this particular employer bears little, if any, responsibility. At the enactment stage, the concern may not be with individual applications, but such applications are inescapable if the law is to be enforced and surely foreseeable at enactment. Third, the pursuit of the redistributive goal is likely to be moderated by a realization that many of those who are competing with the blacks are also in an inferior economic position, that redistribution in favor of blacks may perpetuate or aggravate their inferior position, and that society bears a heavy responsibility for their position too. The legacy of blacks in America may be truly unique, in that the institution of slavery was generally delimited by the color black and few groups have encountered the systematic, widespread and long-enduring illtreatment inherent in Jim Crowism laws and institutions. But other groups also may have been disadvantaged by societal institutions and left with disabilities.

These nagging doubts do not preclude using the legacy notion to justify societal pursuit of a redistributive goal, but they are likely to moderate society's enthusiasm for pursuing the goal. The unanswered question is to what extent it will be moderated.

\section{B. The Need for the Law: The Possibility of Self-Regulation}

An interesting feature of the merit principle is that in a market economy it is to some extent self-enforcing. Employers have an obvious financial self-interest in making employment decisions on the basis of merit. And competition, if not greed, requires or leads them to pursue that self-interest with vigor. Hence, to the extent that a fair employment law does nothing more than prohibit businessmen from making employment decisions on the basis of a nonmerit factor-race-a question arises as to the need for the law.

The need for the law may be predicated on certain intangible values. For example, it may be valuable to reaffirm the principle of fair treatment. This affirmation may produce such nonquantifiable benefits as encouraging confidence in the legal system and encouraging those who believe themselves to be vulnerable to discrimination to compete aggressively for jobs. Reliance upon self-regulation entails a silence that may be pregnant with contrary implications for the likely victims.

The need for the law may also be more firmly rooted. Self-regulation may not materialize because of certain features of our market economy. In a number of situations the self-enforcing capacity of the merit prin- 
ciple is limited, and a risk is created that the employment decision will be based on a nonmerit criterion, such as race. ${ }^{18}$

1. Limits on Profits. For certain industries, government limits profits and thereby removes some incentive for choosing the most productive workers. The employer may not be able to capture the increased return attributable to cutting labor costs, and thus the employer could indulge a discriminatory preference and base his employment decision on race without decreasing his wealth.

2. Equal Productivity. The individuals competing for a certain job may be approximately equal in productivity. This may be the case where the job is highly routinized and can be supervised at low cost. In that situation the competition will ordinarily take place in the realm of wages-who will work for the least amount-rather than in terms of ability. However, wage-rate competition may be precluded because (a) the competing workers are prepared to work at the same wage level or (b) there may be artificial floors on the wage level, such as those established in minimum wage laws or in collective bargaining agreements. Under these circumstances, the power of the market to preserve the integrity of the merit principle is virtually nonexistent. The employer can base his decision on race without decreasing his wealth.

3. Satisfying a Taste for Discrimination in Exchange for Decreased Wealth. An employer may be willing to suffer decreased monetary wealth due to lessened productivity in exchange for the satisfaction of his taste for discrimination. The taste for discrimination may be rooted in many factors, such as the employer's psyche, his political ambitions, or an interest in preserving a social structure that relegates blacks to an inferior position; and the satisfaction of that taste is a type of payment that may offset the decrease in monetary return which may result from disregarding the merit principle. Such an employer may be able to survive in the market because (a) his competitors have similar tastes, (b) he may be selling his product or service in a market where competition is not vigorous, or (c) he may be willing to accept a subnormal return on his capital.

4. Bureaucratization. Considerations of efficiency may lead the business organization to delegate employment decisions to relatively unsupervised agents (for example, the staff of the personnel office). These agents may be more removed from the discipline of the marketplace than is the businessman as a seller. Because these agents usually do not

18 See generally G. BeckeR, THE Economics of Discrimination (1957); Alchian \& Kessel, Competition, Monopoly and the Pursuit of Economic Gain, in ASPECTS OF LABOR EcoNomics 157 (1962); Demsetz, Minorities in the Market Place, 43 N.C.L. REv. 271, 276 (1965); Winter, supra note 11. 
share in the increase of wealth attributable to increased productivity, they have less incentive to apply the merit principle rigorously. Thus these agents may be more able or willing than the employer, at least in the short run, to violate the merit principle to satisfy their own taste for discrimination or that of others whom they wish to please.

5. Employee Control of the Employment Decision. The employment decision may be responsive to, delegated to, or usurped by employees. The classic instance is the union referral system in the building trades. There the contractor formally retains control over the employment decision but in practice the contractor uses the union referral system as his exclusive source of workers. He takes whomever the union sends. And the workers who control the union are removed, at least in the short run, from some of the discipline of the employer's market and thus are more able to indulge their taste for discrimination. The workers are also likely to perceive it to be in their immediate short-run interest to limit the supply of labor (so as to minimize their competition) and to establish criteria for selection, retention and promotion that would benefit themselves without necessarily benefiting the employer. These criteria may well be nonmerit ones.

6. Mistakes. Lack of adequate information about the productivity of individuals may lead the employer to make mistakes. He may make incorrect assumptions about the productivity of blacks because of the general prevalence of racial stereotypes in our society, derived from widespread prejudices and myths generated under the slave regime; or he may make a mistake because of the lack of social and commercial contacts between races, contacts which are often necessary to obtain accurate information about applicants for employment. Moreover, previous employment experience is often the most reliable source of information for accurately applying the merit principle, and it may be unavailable to Negroes because of previous discrimination. The assumption here is that it would pay the employer to obtain accurate information because the increased productivity would offset the costs of obtaining the information, but the employer is unable to perceive what is in his best interest because of these prejudices and stereotypes. ${ }^{19}$

In the above situations the merit principle is not likely to enforce itself; the prospects for effective self-regulation are slim. One irony is that the need for a fair employment law arises in part from the existence of other laws (such as minimum wage laws, laws protecting union hiring halls, laws limiting profit levels, and laws limiting entry) that impair the effectiveness of the market; by interfering with the market, these

19 For an analysis of the problem where such a use of race might not be mistaken (i.e., is not based on stereotypes), see p. 257 infra. 
laws impair the capacity of the merit principle to protect itself. The need for the fair employment law, to the extent that it arises from statutes with a contrary effect, may simply reflect society's reluctance to abandon these other forms of government regulation-it wishes to have its cake and eat it too.

It should also be noted that the enactment of a fair employment law need not be based on the empirical judgment that these situations describe the employment market as a whole. For one thing, the enactment of the law may be predicated on the ethical judgment that, regardless of how infrequently the merit principle is violated, it is extremely important for the legal system to respond to each individual instance of racial discrimination. The existence of a law prohibiting murder is not based on an empirical judgment that we are all murderers, but on the ethical judgment that it is extremely important that the legal system respond whenever there is a murder. Moreover, adjustments could be made in enforcement. The prevalence of situations where the merit principle is unable to protect itself may vary over time, from region to region, from industry to industry, and also from employer to employer. But even with an omnipresent fair employment law covering all areas, all industries and all employers, and not limited in time, adjustments can be made in the decision to enforce or not to enforce, and in the kind of relief sought and given.

In a situation where the merit principle is self-enforcing, employers who deviate from the principle impose costs on themselves. In the other situations there is a need for the imposition of additional costs on the nonmerit employer, and the enforcement of fair employment laws supply those costs. ${ }^{20}$ Indeed, in some instances fair employment laws impose costs on those, such as the building trades unions, who in the short run might not otherwise feel the cost of using a nonmerit criterion in any direct fashion and who, in fact, would benefit because the labor supply would be restricted. Costs imposed by fair employment laws may take various forms-compensatory damages, punitive damages, the obligation to pay plaintiff's attorney's fees, the risk of losing customers (possibly the government), and the psychological or social impact of being adjudged guilty of violating a law that embodies an ethical norm. More drastic kinds of legal sanctions, such as fines and imprisonment, are not usually authorized; and because of continued nonuse, the fear of crimimal contempt for disobedience of an injunction is not immediate. The softness of the available sanctions is one of the unique features of fair employment laws as a regulatory device. This may be a

20 Landes, The Economics of Fair Employment Laws, 76 J. Por. EcoN. 507, 508-19, $545-48$ (1968). 
sign of society's less than full commitment to the antidiscrimination prohibition, or it may indicate either faith that compliance will be voluntary or a recognition that the legal obligation arising from the laws is so unclear that punitive sanctions would be inappropriate.

\section{The Costs of the Law}

All laws have costs, and fair employment laws are no exception. I do not identify these costs in order to determine whether there are less expensive alternatives. ${ }^{21}$ Rather, $I$ am interested in further illuminating the theory underlying fair employment laws by making it clear what price society is willing to pay to achieve the purposes served by these laws.

1. Frustration of Personal Preferences. One set of costs arises from the frustration of personal preferences. A desire to exclude blacks from the work force because of antipathy, a desire to preserve a certain type of social structure, or a desire to associate only with whites, obviously is a personal preference. But, at a minimum, a fair employment law prohibits indulgence of preferences through exclusion of blacks, because of their color, from the work force or from better jobs. This frustration of desire, preference and choice not only has possible individual psychological consequences, but also runs counter to general principles in society insuring freedom of association and the freedom to act upon personal preferences.

Frustration of these personal preferences cannot be ignored on a theory of a political bargain-that the political majority is willing to trade the satisfaction of these personal preferences for the potential increase in total wealth. The view that the law will increase total wealth depends on estimations of the level of wealth without the law (where reliance is on self-regulation), the cost of enforcing the law, and the likelihood that increased use of other nonmerit criteria (for example, nepotism) might negate the effect of abolition of the race criterion. And even if it were possible to make these judgments and be assured that wealth would be increased by the law, it seems impossible to know how much that wealth would increase, that is, whether it would increase to a level at which the

21 For an analysis of some of the alternatives, some of which are not inconsistent with the continued existence of fair employment laws, see generally Brozen, The Effect of Statutory Minimum Wage Increases on Teen-age Employment, $13 \mathrm{~J}$. LAW \& EcoN. 109 (1970); Demsetz, supra note 18 (the free market, and the ability of minorities to offer wealth compensation in the form of lower wages to offset the taste for discrimination); Doeringer \&. Piore, supra note 4, at 327, 336-37 (manpower training programs and their relationship to fair employment laws); Sky, Defense Procurement Preferences as a Remedy for Subemployment: A Comment, 82 HaRv. L. REv. 1266 (1969); Tobin, supra note 13, at 884 (fiscal and monetary policies increasing the demand for labor); Winter, supra note II (the market). 
majority would be willing to engage in the trade-off. Instead, the frustration of these personal preferences must be acknowledged as one price society is willing to pay to achieve the aims of the law. The satisfaction of discriminatory personal preferences of whites entails particularized unfairness and continued relegation of Negroes to an inferior economic position. The law reflects the value judgment-the choicethat eradication of these evils is more "important" than preserving opportunities to vent discriminatory associational desires.

The choice need not be premised only on a hierarchy of values; it may well rest on two other considerations. One is a regard for the associational desires or personal preferences of blacks. The satisfaction of the associational interests and personal preferences of whites might entail the frustration of the desire of blacks to work in a certain company, to pursue a particular career, or to obtain a certain level of income. From the perspective of preserving associational freedom and preferences there is a standstill. The second consideration is that fair employment laws do not completely frustrate these associational desires. These laws may, to some extent, allow satisfaction of associational desires by exempting from their coverage the very small employer. ${ }^{22}$ The assumption is that where there are few employees, associational desires are likely to be most intense. Moreover, a fair employment law may be understood as proclaiming that a business enterprise is an inappropriate forum for the satisfaction of these associational desires. Under a legal regime such as the federal one, where antidiscrimination prohibitions cover public education, housing and public accommodations as well, the individual is remitted to private social clubs and to the choice of friends for the purpose of satisfying these associational desires.

2. Economic Costs. Aside from frustration of personal preferences, fair employment laws, even under the regime of color blindness, involve economic costs. Once again, it would be disingenuous to ignore these costs on the ground that in the long run they will be offset or canceled by increased total wealth due to increased productivity. That view requires an estimate of the economic costs and benefits of the law, which seems, at least to me, unobtainable. The most that can be said is that the color-blind version of the fair employment laws, effectively and cheaply enforced, is consistent with increased productivity. This says very little. It seems more realistic to recognize the economic costs

22 Employers with less than 25 employees are exempt from Title VII of the Civil Rights Act of 1964. 42 U.S.C. $\$ 2000$ e(b) (1964). On various occasions, including October 1, 1970, legislation has been passed by one of the houses changing the number from 25 to 8.112 CoNG. REc. 9153 (1966); S. 2458, 91st Cong., 2d Sess. (1970). Perhaps in a similar vein, Title VII also exempts the employment practices of private membership clubs. 42 U.S.C. $\S 2000 \mathrm{e}(\mathrm{b})(2)$ (1964). See pp. 257.58 infra. 
of the law and to assume that the justification for incurring these costs consists of the nonquantifiable value attached to the aims of the law.

a. The costs of enforcement. Initially, it may seem that the costs of enforcement are relatively insignificant because a fair employment law may be self-executing-almost like the nineteenth amendment. This can occur in four ways. First, the passage of the fair employment law communicates society's disapproval of race-based employment decisions. That general disapproval might be internalized, so that those responsible for the employment decisions conform their conduct to society's sense of moral propriety, if for no other reason than to avoid feelings of guilt. Second, the very existence of the law (perhaps coupled with a low-cost method of enforcement, such as consent decrees) enables an employer who previously discriminated only to avoid alienating customers, white workers or the community to explain to others that he is not "voluntarily" ending his discrimination and to assure them that his competitors are obliged to follow a similar policy. The mere presence of the law might enable him to pursue his self-interest vigorously and to apply scrupulously the merit principle without incurring the loss of sales, goodwill, or white workers that might otherwise flow from nondiscriminatory employment practices. Third, enforcement action against one employer, making him more merit-oriented, may make his competitors, through the operation of the market, more meritoriented in their employment decisions. The effect of one enforcement action can be easily generalized. Fourth, a credible, but general, threat of enforcement may induce employers to conform their employment to the merit principle because satisfying the taste for discrimination becomes more expensive. The employer is exposed to the new risk of a successful enforcement action against him, with its attendant costs.

These four factors have operated with considerable efficacy in obtaining "voluntary compliance" with the antidiscrimination prohibition in another area of economic activity-public accommodations. The same phenomenon seems to be occurring in housing, where the extensive use of a low-cost enforcement method-consent orders-seems to be the rule rather than the exception. In employment, however, the discriminatory pattern seems, at least to the enforcement agencies, more intractable; the prospect of voluntary compliance slim; and the costs of enforcement higher. ${ }^{23}$

23 This statement should be regarded as nothing more than a hypothesis based on personal impressions, and one that needs empirical testing. If the impression is correct, the difference might be attributed to (a) differences in the competitiveness of labor markets contrasted to sales markets, (b) the stringency of the demands of the enforcement agencies in the different areas, or (c) different degrees of willingness of those accused of discrimination to admit violations. 
The costs of enforcing a fair employment law may in part be viewed from the perspective of the plaintiff and the tribunal. Such costs would consist of the resources used by private and public agencies in investigating, prosecuting, adjudicating, mediating, or negotiating claims. There is a corresponding set of costs for the defendant-those actually consumed in defending against claims of racial discrimination. Of course, both sets of costs may be incurred whether or not the claim has merit, and their level may be independent of the outcome of the adjudication.

The risk of incurring litigation costs may, of course, result in nothing more than punctilious compliance with the law. On the other hand, the risk may also lead the businessman concerned with wealth maximization to insure himself against these costs. This insurance would minimize the risk of having to defend against a claim of discrimination and facilitate the defense against any such claim. The price of this insurance can be called an "anticipatory cost" and must be viewed as an economic cost arising from the risk of enforcement.

One form of insurance consists of racial-hiring-hiring, without regard to merit, some of those on behalf of whom claims are likely to be asserted.24 At least the appearance of compliance is established. The price of the insurance is the decrease in productivity attributable to the departure from the merit principle. This may be less than the price of defending (even discounted for the unlikelihood of an enforcement action). Another form of insurance may be the institution of a formalized selection system. Such a system would entail abandonment of subjective criteria (for example, "I liked him"), the substitution of so-called objective employment criteria (for example, the professionallydeveloped, standardized written test), and the establishment of a record-keeping system indicating why an applicant was rejected. The formalized system minimizes the risk of prosecution and reduces the cost of defending because the employer can easily point to performance under these objective criteria (for example, a score on a written test) as his basis for rejecting the individual who charges discrimination based on race. Here the price of insurance is the increased administrative costs of the formalized system, and these may be less than the discounted cost of defending. ${ }^{25}$

24 M. SOVERN, Legal Restraints on Ragial Discrimination In Employment 124 (1966); Winter, supra note 11, at 834-35.

25 Certain criteria utilized in these formalized systems, such as seniority and performance on a standardized test, are now being challenged as violative of the fair employment laws. See pp. 296-310 infra. However, it is clear that the adoption of these systems often coincided with the passage of a fair employment law; and considering the fact that such systems restrict discretion that might otherwise be abused by excluding blacks, see United States 
b. The costs of the obligation: prohibiting efficient decisions based on race. Thus far the prohibition against racial discrimination has been viewed as consistent with greater productivity for the individual businessman and for society. One exception arises when a businessman must expend resources to defend against a bad claim or insure against the assertion of such claims. Perhaps these costs are inherent in any form of government regulation. However, there is another exception, which I find more problematic. It involves the costs imposed on the businessman by virtue of the obligation of the law itself. The mere fact that race itself is not a merit criterion does not mean that the efficient businessman cannot use it for purposes of increasing his productivity. There are at least four situations where the law's prohibition against the use of race precludes the good businessman from engaging in efficient conduct.

(i) Race as a symptom of merit. Some businessmen may concede that race itself is an arbitrary criterion and yet use race in employment decisions on the theory that it is symptomatic of other qualities that are predictive of productivity. For example, they may think that black is a symptom of poor education or high turnover rate. They realize that the symptomatic use of race may not be free of error; obviously, not all Negroes have a poor education or change jobs frequently. But race is an easy criterion to apply, and the good businessman may decide accurately that the savings derived from applying this easy criterion (administrative costs) will offset the costs of occasional mistakes, that is, the loss of increased productivity that might result from excluding Negroes from his work force or from using them only for nonskilled jobs.

(ii) Catering to consumers' or clients' taste for discrimination. A second situation arises when increased productivity due to compliance with the antidiscrimination prohibition will be offset by decreased sales. This would be true under the following conditions: (a) Consumers or clients prefer a firm that discriminates against Negroes by either not hiring them at all or keeping them in inferior positions. (b) Consumers or clients are willing to pay enough to cover the increased costs of labor due to nonapplication of the merit principle. (c) Consumers or clients are able to police the performance of the particular employer to insure that he is discriminating against Negroes. (d) There are alternatives to the consumers or clients so that they need not do business with the complying employer. A decrease in sales would occur only if they

v. Louisiana, 380 U.S. 145 (1965) (holding an interpretation test invalid because it rested unfettered discretion on the registrars), and considering the insurance function of such systems, it is not fair to assume that the choice of criteria reflects a desire to "evade" solely because of the time sequence between the passage of the law and the adoption of the formalized system. 
are able not to consume or to switch to producers of the goods or services who would, for business or other reasons, satisfy their discriminatory preference by not complying. Mere coverage of the industry by a fair employment law will not insure industry-wide compliance, nor will the usual enforcement action directed against the single firm.

(iii) Personnel conflicts. The businessman may decide to limit the number of blacks working for him in preference to increasing the risk of costly personnel conflicts. His thinking is that hiring more blacks will cause the whites to be more antagonistic (because their prejudice has a tolerance level that may be exceeded), resulting in disputes and conflicts among the workers in the course of the workday. This might well be the judgment of the good businessman if three conditions are satisfied: (a) He is correct in his beliefs that increasing the number of blacks will increase the risk of personnel conflicts. (b) His productivity would be decreased if he had only blacks. (c) The costs in productivity due to the exclusion or limitation of blacks are offset by the decrease in costs that might otherwise arise because of the personnel conflicts or because it would be necessary to employ more supervisors to minimize the personnel conflicts generated by higher levels of black employment.

(iv) Wage differentials. Under a limited set of conditions, a businessman who is not interested in satisfying a taste for discrimination but only concerned with wealth maximization may be led to institute wage differentials. These wage differentials reflect more than asserted differences in the employment opportunities of blacks and whites. If that were the only factor, the good businessman would hire all black workers at the low price, inducing whites to offer their services at that price; there would be no wage differential. However, a wage differential might be instituted by the good businessman given two conditions: (a) The first condition is that there are not enough black workers with the relevant skills or abilities to fill the needs of the employer completely, so that the employer must have some white workers. This is certainly imaginable considering the legacy of the black class and the disabilities imposed by that legacy. (b) The second condition is that in order to induce whites to work, it is necessary to pay them more than is paid blacks of equal skill and ability. This need to pay whites more may in turn have two explanations: (1) White workers demand compensation for being unable to satisfy a desire they may have not to associate or work with blacks, a desire that blacks are not as likely to have; or (2) white workers have more job mobility (i.e., alternative opportunities) than blacks because there is more discrimination in the general employment market against blacks than against whites of the same ability.

Conceivably, fair employment laws could be written or construed to 
permit the businessman to engage in those four practices under the limited conditions specified. The theory could be that the employer's decision was not based on the individual's race, but on the employer's interest in wealth maximization. Or it might be said that in these instances the general assumption that race is irrelevant to productivity is wrong. However, that option has not traditionally been chosen. Instead, fair employment laws have been understood to prohibit the use of race as a symptom, to prohibit limiting the number of blacks in deference to customers' taste for discrimination or as a means of avoiding personnel conflicts, and to prohibit the institution of the differential-wage structure. They have been understood to prohibit these practices without regard to whether they are instituted by the good businessman, the one who has no interest but to maximize his wealth. In this regard the norm of color blindness has been pushed to its ultimate limit; a blanket prohibition or per se rule has been adopted. In my judgment, there is good reason for this choice, wholly apart from speculations regarding long-run increases in society's wealth.

First, less than a blanket ban would involve a risk of abuse. The bad businessman-for example, one who uses race simply to indulge his own taste for discrimination-could easily assert a defense to a claim of discrimination. It would be extremely difficult and costly in terms of time, resources and effective achievement of the aims of the law to determine, in the course of an investigation or an enforcement proceeding, whether this particular businessman used race to maximize wealth and whether the conditions specified were satisfied. A justification cast in terms of risk of abuse assumes that it is only in the exceptional case that the use of race could be justified in terms of wealth maximization; per se rules are designed to reflect the usual situation. And there may be some basis for this assumption. Each of the efficient uses of race turns on the presence of carefully specified conditions, and fair employment laws may reflect the empirical view that generally these conditions will not be satisfied, that efficiency can explain only a limited number of instances where race is used. Fair employment laws may be predicated on the view that there is little basis for believing that race is a symptom of another criterion that is predictive of productivity; or that an integrated work force will produce personnel conflict; or that there is a shortage of qualified black workers that would require the employer, for considerations of efficiency, to have some white workers and to compensate the white workers for his inability to satisfy their taste for discrimination. Serious questions can be raised as to the correctness of these assumptions; but, to the extent that these are the factual assumptions underlying the fair employment laws, and, to the extent 
that they are correct, the efficiency-justified uses of race are likely to be viewed by the law as exceptional situations, and the blanket prohibition would be rational. The law is entitled to be unconcerned with the exceptional instances and to formulate an uncomplicated per se rule of law addressed to the likely, rather than the unlikely, situation.

Second, failure to respond to efficiency-based uses of race may have the effect of "honoring" or "legitimating" racial discrimination that cannot be so justified and that ultimately makes a restriction on blacks conducive to short-run efficiency. The employer's use of race may be attributable to consideratious of wealth maximization, but in each instance the use of race relates to someone's taste for discrimination against blacks. It may not be that of the employer. It may be that of his customers, white workers, other employers, or other sellers. This is clearly the case in the customer-catering, personnel-conflict, and wagedifferential situations. It is also true when race is used symptomatically. It is likely that the color black became symptomatic of other qualities (for example, poor education or high turnover rate) that are related to low productivity primarily because of discriminatory institutions and practices, past and present. All these discriminatory tastes and practices would be "accepted" or "honored" if these uses of race were permitted in order to further efficiency. To borrow a concept from the first amendment area, ${ }^{26}$ it would give the bigot a veto. Indeed, in the differentialwage situation the white workers would be provided with an incentive to create the appearance of a taste for discrimination as a means of bargaining for higher wages as the number of blacks hired increased.

Third, to the victim of the employment decision the appearance of the conduct is identical, whether the use of race is efficiency-related or not. The immediate dignitary, psychological, and economic impact on him is identical, and a complicated explanation in terms of the businessman's interest in wealth maximization and the relation of that to social wealth is not likely to be either comforting or believed. It is not irrational for the law to be responsive in part to appearances of injustice, even at the risk of causing some short-run diseconomies. And indeed more than just the appearance of injustice might be at stake. The unfairness inherent in allocating a scarce opportunity on the basis of race stems from two attributes of the racial criterion-unrelatedness to productivity and the absence of individual control. In these four situations the first attribute of race is no longer present; under the conditions specified race would in fact be related to productivity. But the other attribute remains. The individual is being judged on the

26 The analogy is to the "heckler's veto," H. KaLyen, JR., THE NEGro AND THE FIrST AMENDMENT 140.60 (1965). 
basis of his membership in a class and that membership is truly predetermined. I am not certain whether this absence of individual control, even in the special sense connected to race, ${ }^{27}$ is itself sufficient to render the use of race unfair; usually the question need not be faced because the ordinary presumption, contradicted in these four situations, is that the racial criterion is also unrelated to productivity. But it is important to recognize that this attribute of race remains present even in those situations where efficient decisions might be based on race, and may help to explain the law's blanket ban on all uses of race.

Fourth, the good businessman does have some degree of responsibility in these situations. That responsibility stems from his capacity, albeit limited and not free from sacrifice, to work against the underlying prejudices. Holding him legally responsible is not likely to impose crippling costs on any single businessman ("make him go broke," as opposed to being unable to obtain that marginal dollar). It may even create an incentive to work against the ultimate cause. Only in the situation where race is used as a symptom of merit (for example, poor education or high turnover rate) is it unrealistic to assume that the employer has any significant capacity to deal with the underlying cause. In that situation the ban is not likely to lead the employer to improve the public education system or to institute a compensatory training program. $\mathrm{He}$ is much more likely to substitute another easily administered merit criterion (for example, high school diploma or length of time at previous job) that might be as disastrous for blacks as the use of race. In the other situations, however, there are things that the employer might realistically do to combat discrimination. The threatened or actual decrease in wealth might induce him to undertake corrective activities. In the customer-catering and wage-differential situations, for example, there will be an incentive to inform on his competitors who discriminate, for that would lessen his decrease in wealth. In these situations, as well as in the personnel-conflict one, he has an incentive to "educate" whites out of their taste for discrimination. The enforcement process must start at some point, and it is not altogether unwise or unfair to start with him. The other alternatives, such as proceeding directly against those with the taste for discrimination or against all firms in the industry at once, seem in most situations utterly unrealistic. ${ }^{28}$

27 See p. 242 supra.

28 Where employment decisions are made by individual firms, enforcement action embracing all the firms in the relevant sales or labor markets will generally be unavailable. A question would be raised about the faimess of the joinder, and whether the joinder of all the employers would make the litigation or administrative proceeding more difficult to manage and in that sense turn out to be counterproductive. Moreover, the policing of the remedial order that might result would be difficult. This is not to deny that, on 
Fifth, there is no reason why wealth maximization of individual businessmen must be the only value served by the legal system, or a value that must not, under any circumstances, be sacrificed. This is true even though a system legitimating and protecting individual wealth maximization leads to the greatest total amount of goods and services at lowest cost. There are other values to be served, and on occasion they may justify regulation of economic behavior that limits the capacity of individual businessmen to maximize wealth. A clear instance of this is presented in the symptomatic use of race. Regardless of how efficient it may be, the use of race as a symptom of a poor education, and thus as a basis for denying jobs, creates the risk of perpetuating the blacks' inferior economic position, which may in turn result in the members of the class continuing to get a poor education because they remain without the economic power to get the best education. There may, of course, be other ways (for example, providing compensatory education programs) to deal with the effects flowing from efficiencybased use of race, and these may avoid requiring sacrifices by individual businessmen. But there is no reason to believe that these programs will involve less cost for society or that they are politically feasible.

The flat ban against the use of race as a basis for the employment decision is not without its irony. The purported beneficiaries of the law-Negroes-may, as a class, suffer adverse practical consequences. The diseconomies we have been discussing may not stop at simply decreasing the wealth of the businessman. The supply of goods may be restricted because the incentive to the businessman is diminished or the businessman may be able to pass on, through higher prices, some significant portion of the increased costs due to the ban against efficient decisions based on race. Negroes occupy a low economic position in our

occasion, some version of the omnibus enforcement action has been tried. See, e.g., United States v. Sheet Metal Workers Local 36, 416 F.2d 123 (8th Cir. 1969) (originally commenced against several building trades unions in St. Louis when the members of these unions ceased work on the construction of the St. Louis Arch because of the employment of workers who were black and nonunion); Department of Justice Press Release, March 31, 1970, describing an agreement to end discrimination in craft, administrative, and clerical jobs in the motion picture and television industries in Los Angeles (agreement signed by the three major television networks, their four primary supporting craft locals, 73 motion picture producers, their nine craft locals, the International Alliance of Theatrical Stage Employees and Moving Picture Operators of the United States and Canada, and the Association of Motion Picture and Television Producers, Inc.). Even if it is assumed that these omnibus enforcement actions are worth the effort, it should be noted that they are incomplete because they do not deal with discrimination by employers who are outside, for example, the construction industry in the case of the St. Louis Arch litigation or, for example, employers who are outside the motion picture and television industry in the case of the Los Angeles agreement. These employers may be outside the market for the services; but they are part of the relevant market for labor. 
society and thus are likely to feel the brunt of diseconomies that result in higher prices or shortages of goods and services. Moreover, a prohibition on racial wage differentials-a requirement of "equal pay for equal work"-may lessen Negro employment. Under the ban, the businessman loses some of the incentive to hire equally qualified black workers (that is, the savings due to paying them lower pay), for he will have to pay them the same as white workers. And if his costs are higher, he will hire fewer workers, black and white, and the reduction in employment opportunities is likely to hit blacks harder. The paternalism is clear. Some whites, and some blacks, are telling those blacks who might actually benefit from a differential-wage structure that they will not be allowed to accept that benefit because of concerns or interests of the remainder of the class or society as a whole.

Possibly those responsible for fair employment laws did not perceive these ironical consequences of a blanket prohibition. However, the discovery of hidden costs does not mean that the enactment of the law is irrational. For the reasons already discussed, these hidden costs might be significantly less than the costs that might arise if there were no blanket ban, and, in any event, they may simply be one part of the price that society is willing to pay to achieve the more general aims of the law.

\section{Departures FROM the NORM OF COLOR BLindNess: LAW ENForcement Techniques and Judictal Doctrine CONCERNING THE EMPLOYER'S ObLigation}

The theory of fair employment laws formulated thus far is consistent with and indeed supportive of the norm of color blindness. The formulation is, however, incomplete in three important aspects: it does not take account of the techniques necessary to enforce these laws effectively; it does not consider the applicability of these laws to conduct, such as recruitment, not involving a choice among competing individuals; and it uncritically assumes that employment criteria innocent on their face, such as nepotism, seniority, and testing, are beyond the reach of the law. These are serious shortcomings. They pose questions of prime concern to those charged with enforcing and construing the laws. And in answering these questions, the aphorism of color blindness has not helped, nor has it been respected.

To reject the aphorism is not to tolerate, nor to require, preferential treatment based on race-either for whites or blacks. It is not to ignore that the law is committed to an element of symmetry: it is as unlawful to prefer blacks on the basis of their race as it is to prefer whites on the basis of their race. The aim of the law may be to secure 
equality for Negroes, the most likely victims of racial discrimination; but the chosen method for achieving this aim is to prohibit discrimination based on race or color-any race or color. The broad scope of the prohibition-to cover discrimination based on race, without specifying which race-may be attributable to political considerations. Or it may be attributable to an ethical consideration, namely, that the particularized wrong inherent in rejecting a black because of his color is also present when a white is rejected because of his color. The color white is as predetermined and as unrelated to productivity as the color black. The white victim, too, is treated unfairly and unequally.

Arguably, there may be reasons for society to be relatively unconcerned with this unfair treatment of the white victim. It may be assumed that when the victim is white, and thus a member of the majority racial group, the practical consequences of the unfair treatment will be less than when the victim is black. The white victim may be better able to find employment elsewhere. And the wrong may not be accompanied by a dignitary harm; it is not likely to underscore a sense of inferiority. The practical consequences to society might also be less; for example, discrimination against the white might have little or no impact on the general prospects of upward mobility. Moreover, even if unfortunate practical consequences flow from the unfair treatment to a white, society may be willing to permit, encourage or even require that blacks be preferred on the basis of their color in order to further the aggregate economic goal of improving the relative economic position of Negroes. The attainment of social goals is not costless; tolerating this unfair treatment to white victims may be part of the price society is willing to pay to achieve this redistributive goal. ${ }^{29}$

However, these considerations are not relevant for determining whether the law is violated. ${ }^{30}$ The law is structured so that a violation

29 If it can be assumed, for constitutional purposes, that the improvement of the relative economic position of blacks is a permissible goal, an assumption that is probably well-founded in light of the broad historical purposes of the thirteenth and fourteenth amendments, it would be reasonable to conclude that the constitutional guarantee of equal protection does not preclude government from pursuing this redistributive goal in a manner that would inflict particularized wrongs on whites.

30 This is not to suggest that the enforcement agency, in deciding how to allocate its scarce resources, would not be entitled to take into consideration the practical consequences to the individual or to society of the conduct giving rise to the individual wrong. This would be true whether the victim is white or black. Moreover, assuming that the fair employment law is related to the goal of achieving equality for Negroes, the public agency may well formulate a policy that will result in its scarce resources being used predominantly, if not exclusively, to investigate and prosecute claims of racial discrimination against blacks, rather than whites. But this would not alter the legal obligation arising from the law. The decision of an enforcement agency as to its area of primary concern, based on considerations of efficiency and its perception of the aims of the law, 
does not depend on proof of practical consequences; and the particularized wrong occurs without any actual assessment of practical consequences to the victim or society, whether the victim is white or black. Moreover, the importance abstractly attached to the redistributive goal is of limited significance; even if redistribution or equal achievement is the aim, the law is limited in the pursuit of that aim by the terms of the law, which give firm support to the view that society is not prepared to pursue redistribution to the point of inflicting particularized wrongs on whites.

Thus the law is committed to a symmetrical stricture against preferential treatment based on race: preferring a black on the basis of his color is as unlawful as choosing a white because of his color. This stricture is, in my judgment, one of the important limits of the antidiscrimination prohibition. It would be a mistake, however, to equate it with color blindness or to believe that the concept of color blindness adequately expresses or identifies this limit. ${ }^{31} \mathrm{Law}$ enforcement techniques and judicial doctrine have been developed that involve significant departures from color blindness and yet leave this stricture against preferential treatment based on race intact.

\section{A. Law Enforcement Techniques: The Use of Race to Insure Effective Enforcement}

1. Racial Record-Keeping for Enforcement Purposes. At one point in the history of fair employment laws the requirement of color blindness was taken in its most expansive sense. It was viewed as including a ban on racial record-keeping. The antidiscrimination prohibition was thought to preclude any form of record-keeping that identified the race of employees or applicants for employment. This ban is probably at an end. Indeed, not only is racial record-keeping by employers permissible, but employers, unions, and joint apprenticeship committees covered by Title VII of the Givil Rights Act of 1964 are required to submit racial census reports to one of the public enforcement agencies. ${ }^{32}$ Court

does not alter the "obligation" of the law. The obligation of the law-a statement as to what the employer must do and must not do-is not reducible to a prediction of whether the agency will punish him if he engages in certain conduct. The obligation provides the basis for justifying the imposition of the sanction, not just the basis for predicting whether the sanction will be imposed. See H.L.A. HART, THE CONGEPT OF LAW (1961). The agency is free to bring a suit on behalf of a white, however occasional that might be; and the white victim may himself bring a suit, and a defense predicated on the reliance on the practices of public enforcement agencies should have little or no force.

31 Compare Kaplan, Equal Justice in an Unequal World: Equality for the Negro-The Problem of Special Treatment, 61 Nw. U.L. REv. 363 (1966).

3229 C.F.R. §§ 1602.13 (employers), 1602.27 (labor organizations), 1602.20b (joint apprenticeship committees), requiring reports to the Equal Employment Opportunity Commission. 
decrees often require the submission of similar reports to facilitate monitoring of compliance by private and public enforcement agencies. ${ }^{33}$

The ban on racial record-keeping probably did not contribute materially to voluntary compliance with the antidiscrimination prohibition. The ban might have rested on the view that one way of preventing an employment decision from being made on the basis of the arbitrary criterion-race-is to try to keep this information from the decision-maker. But this is a virtual impossibility. Race is like sex and not like religion. It is an easily observable trait, and at some point in the process leading to the employment decision there is likely to be an opportunity for this observation. For example, in the initial hiring situation there is the personal interview; and when promotion or discharge is involved, heavy reliance is placed on the recommendation or evaluation of a foreman or manager who actually supervised the worker and thus is likely to have seen him. Recording the race of the individual on the initial application or on his personnel record provides information that the decision-maker already has or could easily get. The law may be color-blind, but there is no reason to assume that the employer is.

The ban on racial record-keeping not only failed to contribute materially to voluntary compliance; it also made enforcement of the prohibition against racial discrimination more difficult and costly. It kept information known or easily available to the decision-maker from the enforcement agency, which does not have the same opportunities for observation. This information is important to the agency if it uses racial statistics for enforcement purposes; and the permissibility of those uses is discussed in the next section. But the information is also important to the enforcement agency even if the agency does not use racial statistics and instead uses enforcement techniques of unquestionable propriety.

Generally, there are two noncontroversial and highly persuasive ways of detecting and proving racial discrimination. One is admission by the decision-maker. Such an admission is, of course, unlikely, especially where social mores disapprove of the conduct prohibited by the law. A more generally available way of detecting and proving dis-

33 United States v. Sheet Metal Workers Local 10, 3 CCH Empl. Prac. Dec. If 8068 (D.N.J. 1970); Scott v. Douglas \& Lomason Co., 3 CCH Empl. Prac. Dec. If 8006 (N.D. Miss. 1970); Trustees of Tufts College v. Volpe Constr. Co., 3 CCH Empl. Prac. Dec. If 8054 (Mass. Sup. Ct. 1970). See also United States v. Jefferson County Bd. of Educ., 372 F.2d 836 (5th Cir. 1966), aff'd en banc, 380 F.2d 385, cert. denied, 389 U.S. 840 (1967); Lee v. Macon County, 267 F. Supp. 458 (M.D. Ala.), af'd sub nom., Wallace v. United States, 389 U.S. 215 (1967); United States v. Plumbers \& Pipefitters Local 73, 314 F. Supp. 160 (S.D. Ind. 1969). 
crimination is through a method of comparison. This comparison method has three steps: first, identification of the criteria for employment purportedly used by the employer; second, ascertaining how all the applicants performed under these criteria; and, third, comparing how well the successful white applicants satisfied these criteria compared to black applicants. If the comparison shows that jobs are granted with some regularity to white applicants who are, in terms of the criteria, less qualified than the unsuccessful black applicants, the inference of racial discrimination is compelling.

A necessary, though not sufficient, condition for establishing discrimination through the comparison method is for the enforcement agency to know the race of individual applicants. In principle, an enforcement agency could, even without racial record-keeping, identify the race of each applicant by locating and then interviewing him or, if the segregated patterns in housing and education continue, by making inferences from the location of the individual's residence and from the schools he attended (information often included on employment applications and personnel records). But this would be an extremely costly, time-consuming and generally inefficient process. A notation of race on the individual's personnel record is obviously preferable from the enforcement agency's perspective, and it generally does not create any risks that the employment process does not itself contain. In these situations a ban on racial record-keeping makes little sense.

It is true that in Anderson v. Martin the Supreme Court held that noting the race of candidates on a ballot was constitutionally impermissible. ${ }^{34}$ But it is difficult to understand why a state would note race other than to encourage racial choices in election. In our context, where the issue is one of keeping records of the race of applicants for employment, there is an independent legitimate purpose-to facilitate the enforcement process. It is possible to imagine hypothetical situations where there is no opportunity for observation prior to the allocation, or the interviewer or foreman is unable to classify on sight and is either too embarrassed to ask the applicant's race or afraid that asking might create the suspicion of discrimination. In those situations, a rule that precluded the employer from asking the race of the individual might be conducive to compliance and thus would justify a gap in the records. But this would be only an occasional gap; it would not render the

34375 U.S. 399 (1964). The court rested its decision on the equal protection clause of the fourteenth amendment, reasoning that "by directing the citizen's attention to the single consideration of race or color, the state indicates that a candidate's race or color is an important-perhaps paramount-consideration in the citizen's choice, which may decisively influence the citizen to cast his ballot along racial lines." 
remainder of the records useless, nor would it support a generalized ban on racial record-keeping.

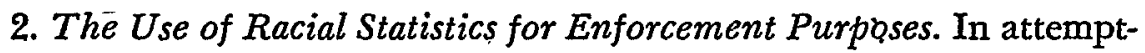
ing to enforce the prohibition against racial discrimination in other areas, such as voting, public education and juries, the enforcement agencies have used racial statistics in three ways: to trigger enforcement action, such as the initiation of an investigation; $; 3$ to shift the burden of proof to the party accused of discrimination-making him prove that he has not discriminated;36 and to formulate the goals of performance required under a decree designed to stop a party from discriminating. ${ }^{37}$ Starting from the realistic assumption that Negroes, rather than whites, are likely to be the victims of patterns of racial discrimination, in each instance the concern has been with low numbers of blacks. That has made the enforcement agencies and the primary decision-makers very conscious of the color black.

Experience in enforcing the antidiscrimination prohibition in employment has been considerably less extensive than in other areas. But there is every reason to expect that these uses of racial statistics will have their analogs in employment, with the likely result that both enforcement agencies and employers will become significantly colorconscious. ${ }^{38}$

a. Racial statistics as a trigger to enforcement agencies. The receipt of an individual complaint should not be a necessary condition for the

35 See, e.g., United States v. Jefferson County Bd. of Educ., 372 F.2d 836 (5th Cir. 1966), cert. denied, 389 U.S. 840 (1967); Letter of John W. Gardner, Secretary of HEW, to members of Congress and Governors, printed in Hearings on H.R. Res. 8261 Before the House Comm. on Rules, 89th Cong., 2d Sess. 31 (1966), explaining that HEW used racial statistics as administrative guides to determine whether an investigation would be appropriate to determine whether free-choice school desegregation plans were working adequately. See also Alabama NAACP State Conference of Branches v. Wallace, 269 F. Supp. 346 (M.D. Ala. 1967).

86 See, e.g., Swain v. Alabama, 380 U.S. 202 (1965); Norris v. Alabama, 294 U.S. 587 (1935) (jury cases); United States v. Louisiana, 225 F. Supp. 353, 385 (E.D. La. 1963), aff'd, 380 U.S. 145 (1965) (voting case); Fiss, Gaston County v. United States: Fruition of the Freezing Principle, supra note 2, at 393 n.43. As Judge Brown put it in Alabama v. United States, 304 F.2d 583, 586 (5th Cir.), aff'd per curiam, 371 U.S. 37 (1962): "In the problem of racial discrimination, statistics often tell much, and Courts listen."

37 United States v. Montgomery County Bd. of Educ., 395 U.S. 225 (1965) (assigument of faculty among public schools so that proportion of white and black teachers in each school approximated the racial distribution of the faculty of the system as a whole); Dowell v. School Bd., 244 F. Supp. 971 (W.D. Okla. 1965), aff'd, 375 F.2d 158 (10th Cir.), cert. denied, 387 U.S. 931 (1967); Swann v. Charlotte-Mecklenburg Bd. of Educ., 311 F. Supp. 265 (W.D.N.C. 1970), cert. granted, 399 U.S. 926 (1970) (teachers and pupils should be assigned so that all schools at various grade levels have the same proportion of black and white teachers and students as there is in the system as a whole).

38 See generally Winter, supra note 11 , at $831-35$. 
commencement of an investigation by a public agency. ${ }^{30}$ While it is true that the victim has an interest in complaining, he may not be aware of the discriminatory basis of an employment decision. Moreover, the individual may fear, perhaps with some reason, that filing a complaint will impose significant costs on him, such as the risk of being blacklisted and being exposed to subtle retaliations (especially in the promotional process) against which the law cannot guard. Finally, the victim may be unaware of the law or of the procedures for commencing an investigation. There is thus some need for the public agency to be self-starting-to initiate its own investigations without waiting for the receipt of an individual complaint. And then there is the need to identify those employers—out of the multitude covered by the lawwho should be investigated. One criterion, by no means the only one, is the likelihood of a violation being found. ${ }^{40}$

To locate probable violations, the enforcement agency can use a combination of factors. There are cultural factors (Where is the taste for discrimination most pronounced?). There are also economic ones (Where are the market conditions such that the taste for discrimination can be indulged at least cost?). These cultural and economic factors identify those situations with the greatest prospect for discrimination. The agency can also use racial statistics, either alone or, for greater effectiveness, in conjunction with the cultural and economic factors to locate probable violations. ${ }^{41}$ The absence of Negroes or a very low number of Negroes in the work force of the employer-a severe racial imbalance-creates a suspicion that the employment practices of this employer are unlawful.

This use of racial statistics is based on the indisputable proposition that one necessary consequence of racial discrimination is racial imbalance. If the employer discriminates against Negroes on the basis of race, there will be no Negroes or very few. This use of racial statistics does not imply that racial discrimination should be reduced to or

39 Blumrosen, Antidiscrimination Laws in Action in New Jersey: A Law-Sociology Study, 19 RUTGERS L. REv. 189 (1965); Blumrosen, supra note 7, at 465-66; M. SovERN, supra note 24 , at $31-35$.

40 A self-starting law enforcement agency might well be concerned with other factors in identifying potential targets. For example, if the goal is viewed as one of equal achievement, the number and quality of jobs that could be made available would be particularly relevant; and whatever the goal, there would be an interest in geographic and industrial dispersion. Such dispersion would broaden the threat of enforcement and perhaps increase the likeliliood of voluntary compliance by employers who would otherwise be inattentive to their obligation under a fair employment law.

41 See, e.g., Cameron Iron Works v. EEOC, 3 CCH Empl. Prac. Dec. ๆ 8064 (S.D. Tex. 1970) (less than $1 \%$ black and less than 2\% Mexican-American white collar employees sufficient to form the basis for the commencement of an EEOC investigation). 
equated with racial imbalance. ${ }^{42}$ Such a reduction or equation would confuse consequence with cause. There are causes other than racial discrimination that may explain the identical statistical consequenceabsence or low number of Negroes. For example, imbalance might be due, not to racial discrimination, but to a lack of the requisite skills in Negroes (perhaps because of their legacy) or a lack of interest of blacks in working for the employer (because of salary level, transportation problems, or the absence of friends). However, since these racial statistics are used merely to trigger an investigation, the likelihood of this conceptual confusion is relatively low. The very purpose of the investigation is to ascertain the true cause of this consequence, to evaluate the "hunch" that the observed racial imbalance is caused by racial discrimination.

b. Racial statistics as a basis for allocating burden of proof. This second use of racial statistics also recognizes the distinction between cause and consequence. The theory is that a total absence or very low number of blacks in the work force is a permissible basis for an impartial tribunal to infer that the employer has racially discriminated. This inference is alleged to be strong enough to create a prima facie case, casting a burden upon the defendant employer to come forth with evidence to prove that the imbalance is not a result of his discrimination and placing the risk of nonpersuasion on him. ${ }^{43}$

When the burden of going forward and the burden of persuasion are reallocated on the basis of this imbalance, the distinction between cause (racial discrimination) and consequence (racial imbalance) tends to be blurred. There is a risk that the distinction will be only a "formal" one. The reallocation of the evidentiary burden might be determinative of the outcome. It may be extremely unlikely that the employer can prove

42 A different rule might prevail in public education, where the imbalance or segregation itself might have an independent significance under the view of Brown v. Board of Educ., 347 U.S. 483 (1954), that "segregated education is inherently unequal." See generally Fiss, Racial Imbalance in the Public Schools: The Constitutional Concepts, supra note 2. In that article I took no account of the relationship between effective law enforcement techniques and racial imbalance, and, instead, premised my analysis on the value of integrated patterns of student assignment-a value that has little counterpart in the employment context. See text at notes 15-16 supra.

43 See, e.g., Parham v. Southwestern Bell Tel. Co., 3 CCH Empl. Prac. Dec. I 8021 (8th Cir. 1970); United States v. Local 38, IBEW, 428 F.2d 144, 151 (6th Cir. 1970); United States v. Sheet Metal Workers Local 36, 416 F.2d 123, 127 (8th Cir. 1969); United States v. Hayes Int'l Corp., 415 F.2d 1038 (5th Cir. 1969); Cypress v. Newport News Gen. \& Nonsectarian Hosp. Ass'n, 375 F.2d 648 (4th Cir. 1967); Chambers v. Hendersonville City Bd. of Educ., 364 F.2d 189, 192 (4th Cir. 1966); Hawkins v. North Carolina Dental Soc'y, 355 F.2d 718 (4th Cir. 1966); EEOC v. Plumbers \& Pipefitters Local 189, 311 F. Supp. 468 (S.D. Ohio 1970). See also Jones v. Lee Way Motor Freight, Inc., $63 \mathrm{CCH}$ Lab. Cas. If 9504 (10th Cir. 1970); EEOC Decision 70-402, Feb. 6, 1970, CCH EmpL. PrAc. Gurde If 8602. 
the cause of the imbalance to have been something other than racial discrimination, or it may be extremely expensive for him to do so. In recognition of this risk, special restrictions should be and generally have been imposed on this use of racial statistics. One condition is that other methods of proof be unavailable to the plaintiff, and a second is that the inference of racial discrimination be supported by other evidence.

In general, reallocation of the burden of proof on the basis of racial statistics is permissible only if the comparison method of proving discrimination is unavailable. There are several reasons why it might be: (1) The race of individual applicants may be unknown. (2) The employees' records may be inadequate. The employer might not preserve applications of unsuccessful applicants. He might not even maintain personnel records, or the records that are maintained may be inadequate because they are limited in time or do not contain, for instance, the test scores or a statement of the reasons for success or failure. (3) The private plaintiff may not have the financial resources to fill these gaps in the records or, even when the records are adequate, to bear the costs always present in this method of proof. These costs are significant when a large number of employees are involved over a significant period of time. (4) The employer's decision may be based wholly or in large part on subjective criteria ("He looked like a good worker to me," "I liked him") that might mask discrimination. In order for the comparison method to be used, some portion of the employer's criteria must be "objective," in the sense that performance is quantifiable; they must permit a ranking of applicants by an enforcement agency that is independent of the employer's. For example, it is possible independently to rank individuals on the basis of scores on a written test and thus to use the comparison method, but not if the employment decision rests wholly on judgments such as "I think he has the right kind of personality." The presence of some subjective elements will not preclude this method. If a pattern emerges where unsuccessful blacks do better on the objective portion than the successful whites, an inference that the subjective portion of the selection process was being abused for discriminatory purposes would be permissible. ${ }^{44}(5)$ There may be no, or very few, Negro applicants, and thus no one to compare with the successful white candidates. This absence of Negro applicants may not be the employer's fault, and in that instance it would be somewhat un-

44 This inference might be neutralized to some extent if it were found that even though unsuccessful black applicants had higher objective qualifications than the successful whites, there were also unsuccessful whites with objective qualifications higher than the successful whites and as high as the unsuccessful blacks. It should also be noted that if there are several criteria, and even if all are objective, it is necessary for an independent ranking that a weight be assigned to each component of the selection process. 
fair to reallocate the burden of proof on the basis of the racial statistics. On the other hand, the absence of Negro applicants may be linked to past practices of the employer that discourage Negroes from applying. Or the absence of Negro applicants may be linked to current recruitment practices of the employer that reach only the white community. Even assuming that these practices themselves are not violative of the law, if they can be established, it would not be unfair to reallocate the burden of proof on the ground that the absence of Negro applicants makes the comparison method unavailable. In these situations, holding the plaintiff to a strict standard of proof, such as the comparison method, and refusing to reallocate the burden of proof on the basis of the imbalance, would tend to honor past discrimination or create incentives for recruitment practices that would not reach the Negro community.

The permissibility of using racial statistics to reallocate the burden of proof also depends on the presence of what can perhaps be considered "supportive facts." The observed racial imbalance, even coupled with a showing that the comparison method is unavailable, is unlikely by itself to justify reallocation. A variety of facts can play this supportive role, although some are not likely to be acknowledged by the tribunal: (1) There may be one or two isolated incidents of racial discrimination..$^{45}$ By themselves these incidents may not be of significance--they may be viewed as "mistakes" or the act of some low-level personnel officer who has been replaced. If that were all, general injunctive relief on behalf of a class might be inappropriate because either the statute or general equitable principles require a pattern of conduct that creates a substantial risk that the discriminatory conduct will recur. But these isolated incidents lend credibility to the inferences arising from the statistics that the employer has pursued a general discriminatory policy. (2) The inference may be supported also by the presence of suspicious circumstances surrounding the employment decision. For example, even though the Negro got the job, he did so only after the classic "runaround." 46 The runaround may itself be a form of discriminatory conduct (unequal treatment), subject to equitable relief; but it might also lend credibility to the inference from the imbalance and thereby warrant more general injunctive relief against the employer, prohibiting him from discriminating on the basis of race in the choice of applicants. (3) The inferences from racial imbalance may be strengthened by considering the context in which the employment decision is

45 See, e.g., Parham v. Southwestern Bell Tel. Co., 3 CCH Empl. Prac. Dec. If 8021 (8th Cir. 1970); United States v. Sheet Metal Workers Local 86, 416 F.2d 123 (8th Cir. 1969); EEOC v. Plumbers \& Pipefitters Local 189, 311 F. Supp. 468 (S.D. Ohio 1970).

46 See, e.g., Dobbins v. Local 212, IBEW, 292 F. Supp. 413, 425 (S.D. Ohio 1968). 
made. ${ }^{47}$ For example, the plant might be located in a community where patterns of racial discrimination have been found by courts or are with good reason believed to persist in voting, public accommodations, jury selection or education. Or the economic context may be one like the referral system of building trade unions, where the prospect for self-regulation by the merit principle is slim. When racial imbalance is found in these cultural or economic contexts, it is not irrational for the tribunal to believe that racial discrimination is a likely explanation for the imbalance.

c. Racial statistics to define performance goals. The first two uses of racial statistics-to trigger investigation and to establish a prima facie case-focus on the actual racial composition of the work force. Concededly, the enforcement agency's concern with the actual racial composition of the employer's work force may induce the employer to establish, on his own, goals that he will seek to attain. One obvious way to minimize the risk of becoming the object of an investigation or to avoid being required to disprove discrimination is to hire a sufficient number of Negroes so that the work force is not unbalanced. But in the third general use of racial statistics-to define a performance goalthe relation between the racial statistics and the employer's conduct is more direct and more explicit. A goal is defined in terms of having a certain percentage of blacks in the employer's work force; and the enforcement agency announces that if the employer's performance deviates from this goal, he will be "punished," unless he can adequately explain the deviation. If the performance goal were embodied in a court decree, the punishment would be a contempt citation or, if the goal were set under the Executive Order, ${ }^{48}$ the punishment would be cancellation of contracts with the government.

This use of racial statistics preserves the distinction between consequence and cause. Noncompliance with the specified goal will not itself be deemed discrimination but merely the result or consequence of discrimination. That is why the employer has an opportunity to show that the deviation from the goal was not the result of discrimination. However, the distinction between cause and conse-

47 The statement of Judge Rives in United States ex rel. Goldsby v. Harpole, 263 F.2d 71, 82 (5th Cir. 1959), is the classic one, not because judges will not take these factors into consideration but because few will explicitly acknowledge that they do. He said: "As Judges of a Circuit comprising six states of the deep South, we think that it is our duty to take judicial notice that lawyers residing in many southern jurisdictions rarely, almost to the point of never, raise the issue of systematic exclusion of Negroes from juries."

48 Exec. Order No. 11,246, 3 C.F.R. 167 (1965), as amended Exec. Order No. 11,375, 3 C.F.R. 320 (1967), 42 U.S.C. \$ 2000e (Supp. III, 1965-67). See generally Note, Executive Order 11246: Anti-discrimination Obligations in Government Contracts, 44 N.Y.U.L. REv. 590 (1969). 
quence becomes extraordinarily formal, perhaps more so than when racial statistics are used as a trigger to investigate or as a basis for reallocating the burden of proof. This is due to the cumulative impact of four features of a performance goal. First, the burden is on the employer to show that the deviation from the goal was not the result of discrimination. The allocation of the burden is inherent in the announcement of the performance goal and does not depend on the satisfaction of any additional conditions. Second, the agency orders or directs that the employer work toward achieving "the consequence," making the achievement of the consequence-the goal-appear to be the obligation under the law. Third, the risk of being "punished" is imminent, increasing the incentive to forget the ultimate obligation and, instead, merely to conform to the performance goal. The ingenious and understanding tribunal may find ways to give the employer who does not discharge the burden "another chance;" for example, the obligation to conform to the performance goal may be understood as an obligation to make "a good-faith effort" to conform to the performance goal and the court may be satisfied that the noncomplying employer has made a good-faith effort. But the employer under such a performance goal should not count on that second chance, and he is not likely to. Fourth, the threat is that if the employer fails to discharge this burden, he will be "punished," not merely put under an injunction couched in general terms.

In order to preserve the distinction between cause and consequence, additional safeguards are necessary. Use of racial statistics to set performance goals should be reserved for the exceptional case where certain conditions are satisfied: (1) There should be a high degree of confidence that the employer has discriminated. This degree of confidence is likely to be satisfied only after an admission or a thorough adjudicatory process, resulting in a particularized and almost unquestioned finding of discrimination. (2) There is little prospect of eliminating racial discrimination through the ordinary remedial processes, that is, by merely restating in an order the general prohibition against discrimination or by requiring the employer to make changes in his employment procedures that might bring discrimination to an end. (3) There should be an evidentiary hearing on the specific terms of the performance goal, that is, on the percentage of blacks that must be attained under it..99

49 In the employment context, the most prominent initial uses of performance goals occurred in the building trades industry. In Insulators \& Asbestos Workers Local $53 \mathrm{v}$. Vogler, 407 F.2d 1047 (5th Cir. 1969), the district court found blatant discriminatory practices and imposed a performance goal in the form of alternating black/white re. ferrals. This solution would eliminate the risk of those operating the hiring hall circumventing any decree that merely ordered the unions to "stop discriminating"; but it is not clear why the risk of abuse could not be curbed by an order establishing priority 
With all three uses of racial statistics-as a trigger to an investigation, as a basis for allocating the burden of proof, and for defining per-

for referrals on the basis of time, with a requirement of record-keeping. In any event, the significance of this innovation may be minimized by the fact that the goal was imposed as part of a preliminary injunction (to expire on the formulation of objective referral standards) and that, at the time the district court imposed the injunction, demand for referrals was very high. Another use of performance goals occurred with the Philadelphia Plan. That plan, which was to apply to federal construction projects or federally assisted construction of $\$ 500,000$ or more, required the contractors to commit themselves in their bids to certain minority representation in the work force on the job. The Plan also specified the following range of minority group representation as being acceptable:

\begin{tabular}{|c|c|c|}
\hline Ironworkers & $\begin{array}{l}\text { lst yr. } \\
\text { 2nd yr. } \\
\text { 3rd yr. } \\
\text { 4th yr. }\end{array}$ & $\begin{array}{l}5 \%-9 \% \\
11 \%-15 \% \\
16 \%-20 \% \\
22 \%-26 \%\end{array}$ \\
\hline Plumbers and Pipefitters & $\begin{array}{l}\text { lst yr. } \\
\text { 2nd yr. } \\
\text { 3rd yr. } \\
\text { 4th yr. }\end{array}$ & $\begin{array}{l}5 \%-8 \% \\
10 \%-14 \% \\
15 \%-19 \% \\
20 \%-24 \%\end{array}$ \\
\hline Steamfitters & $\begin{array}{l}\text { lst yr. } \\
\text { 2nd yr. } \\
\text { 3rd yr. } \\
\text { 4th yr. }\end{array}$ & $\begin{array}{l}5 \%-8 \% \\
11 \%-15 \% \\
15 \%-19 \% \\
20 \%-24 \%\end{array}$ \\
\hline $\begin{array}{l}\text { Sheetmetal Workers, } \\
\text { Electrical Workers, and } \\
\text { Elevator Construction Workers }\end{array}$ & $\begin{array}{l}\text { lst yr. } \\
\text { 2nd yr. } \\
\text { 3rd yr. } \\
\text { 4th yr. }\end{array}$ & $\begin{array}{l}4 \%-8 \% \\
9 \%-13 \% \\
14 \%-18 \% \\
19 \%-23 \%\end{array}$ \\
\hline
\end{tabular}

The legality of this plan has been sustained by the district court in Contractors Ass'n v. Schultz, 62 CCH Lab. Cas. II 9421 (E.D. Pa. 1970), and arguably also by Congress when in December, 1969, it refused to enact a rider to an appropriation bill that was intended to support the Comptroller General's view that the Plan was inconsistent with Title VII of the Civil Rights Act of 1964. Jones, The Bugaboo of Employment Quotas, 1970 Wis. L. REv. 341; Leiken, Preferential Treatment in the Skilled Building Trades: An Analysis of the Philadelphia Plan, 56 CORNELL L. REv. 84 (1970); Hearings on the Philadelphia Plan and S. 931 Before the Subcomm. on Separation of Powers of the Senate Comm. on the Judiciary, 91st Cong., 1st Sess. (October 22-28, 1969) [hereinafter cited as Senate Hearings on the Philadelphia Plan]. I do not believe that there is anything unlawful about the use of performance goals per se, but the three aspects of the use made of them in the Philadelphia Plan seem problematic: (1) The Plan was not preceded by a formal adjudicatory process to determine whether the unions discriminated but by only a wideranging nonadversary hearing. Of course, the absence of such a hearing may be predicated on the presence of widespread beliefs as to longstanding, flagrant discriminatory practices in the building trades unions. See p. 251 supra. (2) The performance goals are addressed to the contractors, not the unions. That limitation may be simply a function of the limitation of the terms of the Executive Order. Or it may be an attempt to get the contractors to police the unions or to force them to develop alternative sources of workers. But this strategy might rest on unrealistic assumptions about the allocation of power in the building trades industry. (3) The opportunity afforded the contractors to explain that the deviation is not due to racial discrimination-by either themselves or their unionsis limited. The employer is given such an opportunity in proceedings to cancel existing contracts and bar future contracting; but the Philadelphia Plan requires that before the 
formance goals-the central problem does not stem from the consciousness of color or, more particularly, from the fact that enforcement agencies are concerned with the number of blacks in the employer's work force. After all, blacks, not whites, were to be the primary beneficiaries of the prohibition against racial discrimination; and blacks, not whites, are the likely victims of racial discrimination. Instead, the central problem is the more mundane one of setting an accurate statistical norm, that is, in determining what proportion of blacks would be in the employer's work force in the absence of racial discrimination. All three uses of racial statistics incorporate some view as to the proper statistical norm. Racial imbalance expresses that view negatively-it is a deviation from this norm. Performance goals express the view affirmatively-you must reach this norm.

In some areas covered by an antidiscrimination prohibition, such as juries and voting, it is relatively easy to construct the statistical norm. It is a function of certain demographic data, namely, the percentage of Negroes of a certain age in the total population of that age in the community. Thus, in voting, for example, the statistical norm could be constructed from the voting-age population; and even if there were literacy tests, a fairly simple index, such as completion of the sixth grade of school, could be used to delineate the relevant racial populations. And such information is easily available in public documents, such as census reports. ${ }^{50}$ However, in the employment area it is more difficult to construct the statistical norm for a particular employer.

award of a particular contract, the employer must commit himself to these performance goals. The employer must make the commitment at the time of the bid, and the commitment is evaluated-the bids are opened-before the awarding of the contract. The contractor may be able to litigate the question of his ineligibility if he cannot, in good conscience, commit himself to these goals at the time of bidding; but the particular contract is likely to be awarded long before that question is ultimately resolved. The businessman interested in wealth maximization is likely to commit himself to these goals and then find a way-some way-to come close to his commitment. For another use of performance goals see the Department of Justice March 1970 agreement with the motion picture and television industries in Los Angeles, described in note 28 supra, which provides for permanent craft jobs a $20 \%$ ratio of minority to white members. See also United States v. Ironworkers Local 86, 315 F. Supp. 1202 (W.D. Wash. 1970).

50 See, e.g., Title I of the Civil Rights Act of 1964, providing in suits by the Attorney General a presumption of literacy based on a sixth-grade education, 42 U.S.C. $\$ 1971$ (c) (Supp. II, 1965). In the cases involving assignment of faculty and students among public schools, see note 37 supra, the statistical norm was constructed from the racial distribution in the system as a whole; the goal provided that distribution should be mirrored in each school and grade. The theory was that, without past discriminatory practices, the races would be so distributed. This, like the judgment as to the statistical norm in employment, seems problematic; but in this context there were two factors to moderate the concern. One is the value attached to integration in public education, see note 42 supra. The second is the absence of competitive unfairness; all the teachers and students were in some school, although their preferences as to which school they were assigned to may have 
In the employment area, demographic data are no more than an informative starting point. (a) The appropriate geographic area of the labor market must also be delineated. People travel to work and the boundaries of political entities usually do not delineate the labor market. These differences are important; for example, if the city is taken as the relevant market, there may be a much higher percentage of blacks than if the entire metropolitan area, including the suburbs, is taken to be the relevant market. (b) An assessment must be made of the skill and ability requirements for the job or promotion, and these vary depending on how much on-the-job training the employer is willing to permit. Moreover, there must be a determination of the relative distribution of these skills and abilities among racial groups. Historical legacies preclude, at least in the near future, the assumption of equal distribution of skills and abilities among racial classes. (c) There also must be a determination of the attractiveness of the job to the relevant racial populations. The attractiveness of a job is, of course, a function of many factors, such as the salary level, regularity of work, fringe benefits, chances for promotion, the pleasantness of the type of work, and geographic accessibility to the job. (d) There must be also a determination of alternative job opportunities and an assessment of the attractiveness of these alternatives in comparison with the jobs offered by the employer in question. The determination of alternative job opportunities must take due account of the prevalence of discrimination elsewhere in the labor market. The level of discrimination would affect the number of alternative opportunities open to blacks with the requisite skills and abilities, which in turn would affect the statistical norm for this particular employer. And that level, of course, varies with the intensity and effectiveness of enforcement actions. (e) Finally, if the question is whether an employer discriminated after a certain date, as is often the case with a newly enacted fair employment law or one with a statute of limitations, it is necessary to take account of the vacancy rate of the employer's work force.

These difficult assessments do not render impossible the task of devising a statistical norm. And there may be ways of accommodating the chance of error. For example, only "substantial" or "gross" imbalance may be used as a trigger for an investigation or a basis for reallocating the burden of proof. Or the enforcement agency may insist upon a "good-faith effort" to comply with the established performance goals and assure the employer that the goals are "flexible." 51 The risk of in-

been frustrated. The issue was not one of hiring teachers or deciding which students should get an education (e.g., college admission)-the true analogs to the employment context.

51 See Senate Hearings on the Philadelphia Plan at 123-39. 
accuracies may also be accommodated by carefully preserving an opportunity for the employer to explain his departure from the statistical norm. However, even with these devices the risk of a mistake in setting the statistical norm persists and, in my judgment, remains quite high. This does not preclude the use of racial statistics. There is no inherent reason why law enforcement agencies should avoid all risks. It would be rational for the legal system to permit even high-risk ventures if the costs of mistakes are small and the promise of benefits significant.

What, then, are the costs of a mistake? First, a mistake in setting the statistical norm, whether it be too high or too low, may impair the integrity and thus the credibility of the fact-finding process of the law. This may be of little concern when only the commencement of an investigation is at stake, for it is permissible for investigators to rely on "hunches" and "suspicions"-views of the facts that admittedly might be wrong. But mistakes are of more concern when the statistical norms are injected into the formalized adjudicatory process. The moral authority or integrity of the tribunals involved in that process, for the litigants and the community at large, in part depends on the accuracy of its factual findings.

A second group of costs may arise where the statistical norm is too low. A level that is too low might let too many discriminators through the investigatory net; it may leave an impossible burden of proof on the plaintiff; and it may result in "tokenism." By hiring a few Negroes, as directly required under the performance goal or indirectly encouraged by the agency's use of racial imbalance, the employer may be able to insulate himself from further investigation or challenge even though he may continue to discriminate. Of course, the seriousness of the "tokenism" risk depends on one's view of the ease with which racial discrimination can be detected or established without relying on statistical enforcement techniques. Or it may depend on how seriously the employer would otherwise take his obligation under the law. A slight increase in the level of compliance-ctokenism"-may be better than nothing. And it is difficult to be concerned about a possible decrease in the employer's attentiveness to his obligation under the law when, in the absence of racial statistics, he would not be attentive at all.

A third set of costs may arise if the statistical norm errs on the high side. One cost is the expenditure of public resources in investigating and adjudicating unwarranted claims. This in turn will involve direct costs for the innocent employer. For example, an investigation initiated because of deviation from an unrealistically high statistical norm may cause, especially in the minds of those interviewed, including present employees and unsuccessful applicants, unwarranted injury to the em- 
ployer's reputation. He may not care about his reputation as a nondiscriminatory employer but he surely cares about his reputation as one who obeys the law. The investigation may also cause the employer to incur certain additional operating costs: labor costs for the time his employees spend being interviewed, the costs of making the company's records available, and the expense of consulting an attorney. Similarly, having to defend by proving that discrimination was not the cause of the imbalance or having to justify noncompliance with the performance goals obviously entails significant costs to the innocent employer, again both financially and in terms of goodwill and reputation. These direct costs are to some extent inherent in any enforcement activity. But when this enforcement activity is guided by a statistical norm that is unrealistically high, these costs to society and the employer increase significantly.

The prospect of such increased direct costs may lead the employer to incur greater anticipatory costs. ${ }^{.2}$ The farsighted and efficient businessman may, in anticipation of greater direct costs, be willing to pay a higher price than he otherwise would for insurance. For example, greater direct costs increase the incentive to institute an elaborate and formal procedure for making employment decisions. There is also an incentive to insure through racial hiring. The incentive to purchase this form of insurance is particularly great because it is more responsive than an objective selection system to the particular enforcement technique in question, namely, using racial statistics. Moreover, if the statistical norm is too high and the employer is pressured to conform to that level, the likely result is that blacks will be hired because of their color, in violation of the merit principle and in violation of the basic prohibition of fair employment laws. The increased labor costs would be the price of the insurance, which might well be below the direct costs of possible enforcement action, even if those costs are discounted by the unlikelihood of it occurring. Racial hiring makes economic sense, particularly when the statistical norm is used to define a performance goal. In that instance, the discount is small because the threatened enforcement action is already particularized and imminent, and because there is a threat made to the individual employer in question that unexplained noncompliance will result in "punishment," not merely in a generally worded decree requiring compliance with the law.

The costs to the public enforcement agencies and businessmen of setting the statistical norm too high cannot be dismissed lightly. There may be a waste of economic resources, and that is likely to have its effect on the public, including blacks, as consumers. Perhaps of even greater

62 See p. 256 supra. 
concern is the irony that, in attempting to enforce fair employment laws through the use of racial statistics, the enforcement agency may set the statistical norm too high and thereby increase the incentives for the employer to violate the law-to hire blacks because of their color. When a Negro is chosen by an employer because of his color solely to meet a statistical norm, which is extremely likely. when the statistical norm errs on the high side, a white is being denied the opportunity or is being discriminated against because of his color.

Notwithstanding these costs, there are three factors that might justifiably moderate one's concern with the risk of erring on the high side in setting the statistical norm. One is a judgment that even though the statistical norm is set too high, there remains an incentive on the part of the employer to base his decisions on merit. The benefits from increased productivity through merit hiring might offset whatever costs might be involved in answering or responding to charges of discrimination. These benefits might not neutralize the incentive to use racial hiring to create the appearance of compliance, but they place some ceiling on the incentive.

Second, assuming a heavy white majority in the relevant constituency, political pressures are likely to lessen the risk that the statistical norm will err on the high side. Although enforcement agencies are not as responsive to political majorities as are legislative bodies, they are not entirely autonomous. There is always the possibility that the majority will change or amend the law. Courts rely in large part on the confidence of the community - the whole community-for their authority; administrators have similar needs. Indeed, administrators are particularly vulnerable to political pressures through the appropriation process. As long as the political majority remains white on the national or state level and the affected employers can bring their claims to the political forum, there is little likelihood that the statistical norm will consistently be set too high.

A commitment to the redistributive goal is the third factor moderating the concern with the chance of the statistical norm erring on the high side. An error of this type would be more tolerable if the aim of the law were thought to be equal achievement-increasing the slice of the economic pie for Negroes. The chosen strategy of the legal systemthat of prohibiting racial discrimination-acknowledges limits to the majority's willingness to pursue the redistributive goal. But these statistical enforcement techniques may fall within those limits. Only the possibility as opposed to the certainty of unfair treatment or violation of the law is created by the error. As we have seen, the very existence of a fair employment law may provide incentives to engage in racial hiring 
as a form of insurance against enforcement; and a statistical norm that is too high merely increases those incentives. Moreover, the conduct that increases the incentives to engage in racial hiring is undertaken in efforts to enforce that prohibition effectively and efficiently. The agency may be misenforcing, but presumably only inadvertently.

The difficulties inherent in determining the proper statistical norm and an awareness of the costs of an error compel caution, but not the conclusion that all such uses of racial statistics are impermissible. These uses of the racial statistics promise certain efficiencies in the law enforcement process that might well offset the decrease in overall productivity stemming from the costs of mistakes to society. More importantly, it should be understood that the realistic alternative to enforcement techniques employing racial statistics is underenforcement. I have confined the uses of such statistics to situations where other techniques for effective law enforcement are not available. To forbid the use of racial statistics even in these situations would severely limit the prospect of effective enforcement of the fair employment laws. This would mean a continued preference of whites because of their color-certainly as much a violation of the law as preference for blacks because of their color. The question should not be one of ever permitting the use of racial statistics for enforcement purposes but, rather, whether in each case the appropriate conditions are satisfied and whether the statistical norm is accurate.

B. The Employer's Obligation Under the Law: The Evolution of Doctrine Rendering It Sometimes Necessary and Permissible for the Employer to Consider Race

The use of race by the enforcement agencies may create incentives, often powerful ones, for the employer to prefer blacks in his employment decisions. Beyond that, the employer's obligation under the law has, in some situations, been construed to permit and indeed require the employer to consider race and to engage in conduct that confers benefits on a class that is predominantly, if not exclusively, black. This conferral of benefits is claimed to be a form of preferential treatment of blacks. The appropriate response is not to resurrect the concept of color blindness but to determine whether this conferral of benefits constitutes a preferential, rather than equal, treatment and whether it is based on race or some other factor.

1. Conduct Not Involving a Choice Among Competing Individuals. A fair employment law is a device for regulating employment decisions, and, as we have seen, an employment decision is analyzed primarily as a choice among several individuals competing for a limited number of 
opportunities. The competitive paradigm emphasizes the judgmental quality of an employment decision-picking the best individual. It explains the sense of unfairness when a decision is based on an arbitrary criterion. It also emphasizes the two-dimensional quality of all benefitgiving activity: to give the job to one person is to deny it to another. But this paradigm might be too limited. The employer can engage in conduct that greatly affects his employment decisions but that itself does not involve a choice among competing individuals in the sense that awarding a job does. The most familiar example is the distribution of information concerning job openings. There is considerable doctrine that construes the antidiscrimination prohibition to permit, and sometimes even to require, employers to engage in informational programs addressed or tailored to blacks. Often the government conducts or subsidizes such programs.

The initial question to be asked concerns permissibility: Can such informational programs be reconciled with the antidiscrimination prohibition? An affirmative answer depends on two propositions: (a) the conferral of benefits on the class is not based on race but on the special informational needs of the black community; and (b) the benefit conferred is a limited one-not awarding a job, but merely giving information that is generally available to other groups and that is arguably not available to blacks because of general patterns of discrimination.

A tribunal faced with a challenge to a black recruitment program may conclude that, even though the benefit (information) is conferred on a class of persons consisting primarily of blacks, it is not conferred because of their race but because of their special needs. These needs may be of two varieties. The first relates to the lack of knowledge of job opportunities. The assumption is that the availability of job opportunities is primarily known by word of mouth, through people who are working with or known to the employer, ${ }^{53}$ and that the paid advertisement is used only when these informal methods are inadequate. Admittedly, some whites do not have access to word-of-mouth information, but the assumption is that blacks, as a racial class, are more likely than whites not to have access to most of this information. This may be a function of all-white work forces, as well as segregated residential, social and educational patterns, all of which have the effect of limiting the opportunities blacks as a racial class have to come into contact with those

53 See, e.g., Marshall \& Van Adams, supra note 4, at 314: “'Employee referrals' was the source most consistently used by employers $(83.0$ percent of the 52 employers responding to this question used this source) and most frequently ranked as effective for recruiting white-collar employees (58.1 percent ranked it as effective) . . . . [F]or employers, 81.0 percent of those responding used the state employment office, but only 30.9 percent viewed it as effective for recruiting white-collar employees." 
who are likely to know of employment opportunities. Concededly, these segregated patterns may be attributable to many factors, but the further assumption is that they are in large part due to discrimination against blacks. The alleged second special need is invitational: blacks not only have to be told about the vacancy, but they must also be invited to apply. The assumption here is that blacks may hesitate to apply because they fear they will be victims of discriminatory practices. This fear may be irrational; but, if rooted in past discriminatory practices of the employer, the industry, or the geographic area, it is likely to be quite rational. An informational program addressed to the black community not only gives information otherwise unavailable but also conveys, implicitly or explicitly, an assurance that the employer will not discriminate against blacks because of their race.

Although race is not the basis of conferring these benefits, it is often used as the primary, though perhaps not exclusive, identifying characteristic of the class of persons to whom the information is addressed. In this sense, the color black is used symptomatically. It indicates the class of persons likely to have special informational needs, and the symptomatic relationship between race and these needs is no accident. The needs of blacks are assumed to be caused in large part by discrimination against the racial class. Of course, there may be some blacks who do not have these special informational needs. But the empirical assumption is that, in the generality of cases, it is accurate (and perhaps that the cost of an error is not high). Nor is there a fatal inconsistency in forbidding the symptomatic use of black for imposing disadvantages, such as denial of jobs, while permitting the symptomatic use of black for conferring this limited type of benefit-giving information about job openings that is generally available to other groups. This asymmetry does not seem paradoxical in light of the limited nature of the benefit and the aggregate economic goal of the law, that is, improving the relative economic position of Negroes. Perhaps the asymmetry can be explained also in terms of the unverified empirical proposition that race is a more accurate symptom of "having special informational needs" than it is of "low productivity."

Though the identifying criterion is race, often, but not always, it is camouflaged. For example, the addressees may be described in terms of residence ("the inner-city residents"), or attendance at certain high schools ("the ghetto schools"), or membership in certain organizations ("community action organizations"), or economic status ("the hardcore unemployed"). These choices of nonracial labels reflect a desire to avoid even the appearance of a conflict between the program and the antidiscrimination prohibition. Yet the legality of these programs has not, 
and should not, turn on the choice of label. The employer or public agency that acknowledges the racial contours of the benefited class is not only franker but it is likely to be more efficient.

Presumably, it would not be permissible to design a similar informational program addressed to whites. And to that extent the normative equivalence of the colors white and black breaks down. This asymmetry can be explained on the theory that a class identifiable primarily by the color white does not have the same informational needs as does a class identifiable primarily by the color black. Of course, there may be other minority groups in our society that have these special needs, for example, Mexican-Americans, Puerto Ricans, Appalachians, or the rural poor. But instituting an informational program addressed to blacks does not preclude the employer or the government from extending the program to groups with similar needs; nor does the law condition its willingness to permit special informational programs for blacks on the willingness of the employer or government to undertake similar programs for all minorities. In this regard, it is possible to move step by step. $^{54}$

The permissibility of a black-recruitment program turns not only on the alleged existence of these special informational needs and the symptomatic relationship between the color black and these needs, but also on the limited nature of the benefit conferred. Undoubtedly there is a benefit conferred. The information is more than the recipients might otherwise receive; and it helps them to obtain employment opportunities. Moreover, because scarce resources are consumed by the informational program, a benefit is conferred on one group that is not conferred on another. But the benefit is limited in two senses. First, the information is of a very general nature. The assumption is that the information distributed would be available to a significant number of blacks (the class benefited) if there were no discrimination in society, and it is the kind of information that others have. For example, the informational program could advise that there are openings in the apprenticeship program of a building trades union and announce the procedures for applying. This information is, in a sense, public-although not every member of the public may have it. It is not suggested that the informational program would be consistent with the antidiscrimination prohibition if it gave information not generally available, such as the answers to a test or an early announcement of the time for applying for positions awarded on the basis of the time of application. Second, the benefit is limited because only information, and not a job, is being given. The redistributive

54 See, e.g., McDonald v. Board of Election Comm'rs, 394 U.S. 802 (1969); Katzenbach v. Morgan, 384 U.S. 641 (1966). 
quality of this benefit-conferring activity is not pronounced. True, an increase in the number of blacks hired may be one consequence of the information program, and that may well be one of the underlying aims of the program. Indeed, an actual increase in the number of blacks hired is one of the most effective ways of recruiting black applicants and almost a necessary condition of an effective recruitment program. It lends credibility to the implicit message in any informational program, namely, that hiring is on a nondiscriminatory basis. Yet the information program can be separated from one of its possible consequences. The racial composition of the universe of applicants might change and that might lead to an increase in the number of black employees. But it need not, and the assumption ${ }^{55}$ is that the assembled universe will be treated in accordance with the antidiscrimination prohibition and that, if there is an increase in the number of black employees, it will not be due to hiring on the basis of race. The unfairness to a white inherent in rejecting him for a job on the basis of his color is not necessarily present; this lessens the burden that must be shouldered by those who argue for special informational programs for blacks and the stricture against preferential treatment based on race is thereby left intact.

In addition to the question of permissibility, there is also the duty question: Does the antidiscrimination prohibition oblige employers to engage in a special informational program? In approaching this question, its practical siguificance should be kept in perspective. It should be recognized that the businessman has several incentives to institute "voluntarily" such an informational program. First, information distributed to the black community may be a relatively inexpensive way of increasing his supply of labor and thereby cutting his labor costs. The assumption need not be that blacks are more productive, but rather that they constitute a ready reservoir of workers who are likely to be willing to work at low wages and, further, that the traditional informational mechanisms have not been adequate to reach this supply of labor. Second, just as some businessmen may be willing to make monetary sacrifices to satisfy a taste for discrimination, others may be willing to make a similar trade-off to satisfy a taste for responding to the special needs of the black community. This may increase their happiness directly, or indirectly by pleasing their friends, relatives or peer groups. Third, the employer may incur the costs of these programs in anticipation of enforcement action. Faced with actual or likely

55 Contrast Professor Blumrosen's proposal for a so-called "affirmative action file," supra note 7, at 488: "This contemplates a recruitment procedure whereby the employer seeks apphications from minorities, reviews them, and places the presumptively qualified minority group applications in a separate file. He reviews this file first when vacancies arise and will hire from it unless he has compelling reasons not to." 
charges of discrimination, the businessman interested in wealth maximization may institute an informational program to reduce the risk of enforcement action. It serves an insurance function like the objective decision system or the racial hiring program; the direct costs of an enforcement action (even discounted by its unlikelihood) are greater than the price of the insurance. In many respects this insurance policy is somewhat more attractive than the others. Unlike an objective decision system, the publicity value of these programs is high. In contrast to racial hiring, this type of activity is acceptable to competing whites because they realize that the benefit to blacks is a limited onereceiving the information does not guarantee receiving the job. This form of insurance does not involve the same kind of individual unfairness as racial hiring. And the economic price of the insurance is low; it consists of the cost of transmitting the information (sending an announcement to an organization, or purchasing advertisements in news media, or having a representative of the company make public appearances), and the cost of processing an increased number of applications. Indeed, in many instances, the price of the insurance to the employer may be subsidized by the government (through "outreach" grants) ${ }^{56}$ Moreover, even if these incentives are not sufficient to lead businessmen to adopt voluntarily such informational programs, the willingness of the government to maintain its own programs (such as the Apprenticeship Information Center) and the incentives and opportunities for the black community to establish programs for distributing job information (such as that of the Urban League) lead me to believe

56 These factors probably account for the popularity of these outreach programs with the building trades unions. See, e.g., Statement of Louis Sherman, General Counsel, Building and Construction Trades Department, AFL-CIO:

... Our opposition to the amended revised Philadelphia plan of September 23, I969, should be viewed in proper perspective. The Building and Construction Trades Department at its 55th convention (September 22, I969) adopted a comprehensive statement of policy on equal employment opportunity. The following excerpts from this statement of policy show the favorable attitude of the building and construction trades to the equal opportunity program and some of the achievements of the trades in this regard:

"The Building and Construction Trades Department and its affiliates have not contented themselves with so-called passive non-discrimination programs. Whether or not legally required, the Department and its affiliates have undertaken affirmative action to increase Negro employment in the building and construction trades. At its 1967 Convention, the Building and Construction Trades Department adopted a resolution stating that it 'endorses generally the principle of affirmative action to assist Negroes and other minority group persons in finding suitable employment and improving their economic and social status.' In a later communication from the President of the Department to the Secretary of Labor, the Department proposed to implement the resolution, among other things, by fostering 'with the cooperation of appropriate management organizations programs of recruitment of qualified applicants for apprenticeship from the Negro population and other minority groups." "

Senate Hearings on the Philadelphia Plan at 163. 
that the duty question is not nearly as significant as the permissibility question..$^{\text {s7 }}$

In approaching the duty question, it should be understood also that the question might arise in two quite distinct contexts. In one, the question arises incident to formulating a comprehensive decree against an employer, and in the other the duty question is the sole question of discrimination. In the first context, there is a finding that the employer has discriminated on the basis of race in his employment decisions, and the problem is one of determining the terms and scope of the decree. From this perspective it seems fair to require the employer to institute a special informational program. Indeed, for the reasons already suggested, the employer is most likely to consent to this facet of the decree. To the extent that the employer has excluded blacks from his work force he has blocked one source of knowledge for the black community about job openings, and it is more rational for blacks to feel that they are not welcome. There is a need for an invitation. Moreover, the financial costs of the special informational program are likely to be viewed from a compensatory perspective-the sacrifice in wealth due to the additional expense of the program is appropriate since the employer's wrongdoing gave rise to the special informational needs.

This judicial practice is fairly typical ${ }^{58}$ and thus represents a departure from the norm of color blindness. However, the willingness of tribunals to answer the duty question affirmatively in this limited context should not be mistaken for the emergence of a general duty to respond to the special informational needs of the black community. It is a well-established principle that a decree may hold a defendant who has violated a legal prohibition to a higher standard of conduct than that required by the prohibition itself. The decree should not only prevent discriminatory employment decisions from occurring but also eradicate the effects of those decisions. ${ }^{59}$ The fact that a decree requires an employer to engage in certain conduct does not necessarily mean

57 See generally F.R. Marshall \& V. Briggs, The Negro and Apprenticeship (1967); Marshall \& Van Adams, supra note 4, at 317-18, 321-22; Pinkus, The Workers Defense League, in Programs to Employ the Disadvantaged (P. Doeringer ed. 1969).

58 See, e.g., United States v. Sheet Metal Workers Local 36, 416 F.2d 123 (8th Gir. 1969); United States v. Iron Workers Local 392, 3 CCH Empl. Prac. Dec. I 8063 (E.D. Ill. I970) (consent decree); United States v. Plumbers \& Pipefitters Local 173, 314 F. Supp. 160 (S.D. Ind. 1969); United States v. Operating Eng'rs Local 520, CCH EMPL. PrAc. GuIDE If 8115 (E.D. Ill. 1969).

59 See, e.g., Louisiana v. United States, 380 U.S. 145 (1965); United States v. E.I. du Pont de Nemours \& Co., 366 U.S. 316 (1961); United States v. National Lead Co., 332 U.S. 319 (1947); Porter v. Warner Co., 328 U.S. 395 (1946); Phelps Dodge Corp. v. NLRB, 313 U.S. 177 (1941); Warner \& Co. v. Lilly \& Co., 265 U.S. 526 (1924); United States v. Alabama, 304 F.2d 583 (5th Cir.), aff'd per curiam, 371 U.S. 37 (1962). 
that the prohibition of its own force legally obligates the employer to engage in that conduct.

From this perspective, where there is no finding of actual discrimination in the employer's decision, I do not understand the antidiscrimination prohibition to oblige employers to respond to the special informational needs of the black community and much less to produce an integrated universe of job applicants. The general legal duty is for the employer not to discriminate on the basis of race. In the recruitment context, this means that race must not be the basis for determining the addressees of a prograin distributing information about jobs. This rule is applicable even if the employer believes that the color white is symptomatic of greater productivity or even if the recruitment of whites would be conducive to economies because it satisfies the discriminatory desires of workers or customers. ${ }^{60}$ When the plaintiff can prove that an employer's informational program is not based on costs but on race (or, with a shift of the burden, the defendant is unable to prove that the program is based on costs), then a remedial order could appropriately require the employer to adopt recruitment practices to neutralize the effects of previous practices and minimize the risk of future discrimination in recruitment. A special informational program would serve both purposes.

The troublesome case is where the recruitment program is based on costs, rather than on the race of the addressees, and yet (a) the persons most likely to receive the information are white and (b) that is foreseeable by the employer. This might occur when the optimum advertising (that reaching the most people at the lowest price) for workers is that placed in newspapers not generally read by the black community. Or, as is more common, the employer might rely exclusively on walk-ins or word-of-mouth recruitment by present workers. The addressees of word-of-mouth recruitment will be white only if most of the present workers are white; but it is important to emphasize that the context we are now discussing is one in which it has not been established that the racial homogeneity of the work force is due to exclusion of Negroes based on their race.

An argument might be constructed to bring this troublesome case within the reach of fair employment laws. One such argument would build on the situation where (a) the program was cost-justified but (b) the result (reach only whites) was predictable and (c) the employer desired that result because he wanted to exclude blacks from his work force (in order to satisfy his taste for discrimination or that of his workers or customers). The argument would be that the "true basis" of

60 See pp. 257-63 supra. 
the program was race rather than cost. A second argument might simply maintain that it is too difficult for the law to determine whether this predictable or foreseeable result-a universe of white addressees-is based on costs, as opposed to the race of the addressees. Rather than engage in such difficult inquiries, the argument continues, the law should be construed to require informational programs that would, without prohibitive expense, include black addressees and tend to improve the economic position of Negroes-one of the purposes of fair employment laws. ${ }^{\text {eI }}$

Neither argument is particularly persuasive. The second argument fails simply because the recruitment practices most in controversy, such as personal referrals or walk-ins, seem on their face to be most economical. That is no doubt why they are so common. Hence it would be somewhat disingenuous to place much weight on the assertion that it is difficult to determine whether a recruitment practice is cost-justified. Moreover, the argument predicated on the situation where the program is cost-justified and yet the result coincides with the discriminatory desire of the employer is not decisive; it may be argued with equal force that the "true basis" is the cost-justification (for he would not incur any additional costs to satisfy his desire). And it should be recognized that a decree prohibiting the employer from engaging in such a cost-justified practice would, by definition, impose inefficiencies on him and thus transgress one of the limitations generally recognized by fair employment laws.

In such a situation it seems appropriate to reflect on the value to the legal system or society of adopting such an argument. Quite frankly, I see little gain. Since, by and large, the market will insure that the employer will choose the cost-justified form of recruitment, it is unlikely that the announcement of a general duty to respond to the informational needs of blacks will itself radically alter the nature and terms of recruitment practices and induce employers to adopt voluntarily such programs. The self-interest of the employer and the forces of the market will lead him to choose the cost-justified form of recruitment, regardless of whether it will produce an integrated pool of applicants. The regulatory power of self-interest and the market may also lessen the need to impose a duty. The very existence of a fair employment law is testimony to the fact that the regulatory power of the market is not fully adequate, but this is not to deny the regulatory

61 See generally Blumrosen, supra note 7, at 474-79. "Thus the mechanisms by which the flow of job applicants is all white may vary, but the result of these mechanisms is the same. The all-white character of the labor force is perpetuated to the knowledge of the employer. The system violates title VII." Id. at 479. 
power of the market altogether. Perhaps the market can be trusted to take care of the narrow situation where the tribunal has difficulty in determining that a recruitment program is based on costs rather than the race of the addressees. Moreover, there are strong incentives for the employer to institute voluntarily a special informational program, and there seems little need for additional incentive in the form of a judicial command. Finally, the opportunities in this area for self-help are considerable. Any black organization can amplify the addressees of recruitment programs by making the information available to blacks. The expense of doing that is minimal, and there are a significant number of government programs willing to subsidize that form of self-help. If the concern is with furthering the relative economic position of blacks, then the pressure could and should be maintained at the point where there is little opportunity for self-help-the employment decision. An attack upon the recruitment practices of an employer may be considerably easier than an attack upon employment decisions themselves; it is easier to detect whether the recruitment reaches an integrated audience than whether the employer chooses applicants on the basis of race. But it seems that the perfection of enforcement techniques, and not the announcement of a general duty of integrated recruitment, is the only appropriate and effective response to that problem.

I would therefore venture to guess that the duty question of recruitment, abstracted from the context of formulating a more comprehensive decree dealing with discriminatory employment decisions, will be thrust upon tribunals in rather artificial situations. It may be made the sole issue of a lawsuit brought by the subsidized lawyer who receives part of his compensation in terms of the satisfaction he derives from being thought responsible for "novel" or "far-reaching" doctrine. Or it may be the position of a litigator who is unable to prove that the employer discriminates on the basis of race in his choice among applicants. Or it may be raised because the black organizations and the employer are conducting an "ideological" battle on the issue of how "responsive" the employer must be to the needs of the black community. ${ }^{62}$

2. The Evaluation of Facially Innocent Criteria. The choice among individuals competing for a particular employment opportunity is often made on the basis of criteria that are allegedly applied to both Negroes and whites-facially innocent criteria. For example, applicants for a

62 See In re Allen Bradley, CCH EMpl. Prac. Guide If 8065, 8070 (Office of Fed. Contract Compliance 1968, 1969) (the impermissibility of using walk-ins based on the affirmative-action part of the Executive Order rather than on the prohibition against discrimination). See pp. 310-13 infra. See also EEOC Decision 68-2-724E, Sept. 9, 1969, 49 EEOC Dec. \6066. 
job may be judged on the basis of their performance on a written test. Graduation from high school or the absence of an arrest record may be required of all new employees. There may be a requirement that present members of the work force vouch for the applicant's skill and reliability or that the applicant be related to a present employee or member of the union. A referral by a building trades union may be conditioned on the applicant having worked in the industry for a certain number of years. Or a preference in promotions, layoffs, recalls, or referrals may be given to those employees with the most seniority. ${ }^{63}$

On one level, these criteria seem immune to a challenge based on the antidiscrimination prohibition because they seem to apply to both Negroes and whites. However, in enforcing the antidiscrimination prohibition in other areas, particularly voting, ${ }^{64}$ the use of analogous facially innocent criteria has not been immune to challenge. The courts have vigorously probed below the surface and have, in some instances, found that the use of these criteria violated the prohibition. A similar pattern is emerging in the enforcement of fair employment laws. But I believe that the pattern in employment will have different contours and will be less far-reaching than that in voting. The difference will be due, first, to the predominance of scarcity which has the effect of underscoring the competitive relationship among the applicants for jobs and, second, to the self-regulatory nature of the market place.

a. The universe of persons to which the criterion is applied: cheat-

63 See generally Jones v. Lee Way Motor Freight, Inc., 63 CCF Lab. Cas. If 9504 (10th Cir. 1970) (transfer prohibition); United States v. Local 38, IBEW, 428 F.2d 144 (6th Cir. 1970) (work experience); Griggs v. Duke Power Co., 420 F.2d 1225 (4th Cir.), cert. granted, 399 U.S. 926 (1970) (high school diploma equivalency tests); Papermakers \& Paperworkers Local 189 v. United States, 416 F.2d 980 (5th Cir. 1969), cert. denied, 397 U.S. 919 (1970) (seniority system); United States v. Sheet Metal Workers Local 36, 416 F.2d 123 (8th Cir. 1969) (prior work experience); United States v. Hayes Int'l Corp., 415 F.2d 1038 (5th Cir. 1969) (seniority, prior work experience); Insulators \& Asbestos Workers Local 53 v. Vogler, 407 F.2d 1047 (5th Cir. 1969) (nepotism, prior work experience); Gregory v. Litton Systems, 316 F. Supp. 401 (C.D. Cal. 1970) (arrest record); United States v. Bethlehem Steel Corp., 62 CCH Lab. Cas. I 9448 (W.D.N.Y. 1970) (transfer, seniority); United States v. Plumbers \& Pipefitters Local 73, 61 CCH Lab. Cas. I 9329 (S.D. Ind. 1969) (nepotism); United States v. H.K. Porter Co., 296 F. Supp. 40 (N.D. Ala. 1968) (seniority, tests); Dobbins v. Local 212, IBEW, 292 F. Supp. 413 (S.D. Ohio 1968) (prior work experience); Quarles v. Philip Morris, Inc., 279 F. Supp. 505 (E.D. Va. 1968) (seniority); State Comm'n for Human Rights v. Farrell, 48 Misc. 2d 958, 252 N.Y.S.2d 649 (Sup. Ct. 1964) (nepotism, tests).

64 See, e.g., Gaston County v. United States, 395 U.S. 285 (1969); Louisiana v. United States, 380 U.S. 145 (1965); Guinn v. United States, 238 U.S. 347 (1915); Fiss, Gaston County v. United States: Fruition of the Freezing Principle, supra note 2, at 382 . I have also analyzed the applicability of the fourteenth amendment's equal protection clause, whose language differs from the prototype considered here, to another type of facially innocent criterion-a geographic criterion-as a basis for assigning students to public schools. Fiss, Racial Imbalance in the Public Schools: The Constitutional Concepts, supra note 2, at 588. 
ing and implicit exemptions. One source of concern may be the universe of persons to which the criterion is applied. In spite of its nominal innocence, a racial class may be exempted by the employer from its application. The exemption may be created covertly when the employer "cheats"-he does not fulfill his promise to apply the criterion alike to both Negro and white. It turns out, on closer inspection, that the criterion is not applied to whites although it is applied to Negroes, or it is not applied to whites in the same manner that it is applied to Negroes. For example, the employer may hire or promote only those Negroes who pass the test, but hire or promote whites whether or not they pass the test; or he may score the test of a white more leniently than that of a black. ${ }^{65}$

Such cheating is exceedingly difficult to detect and establish as an evidentiary matter. The endeavor is hopeless unless performance under the criterion is quantifiable and unless accurate records are maintained; and even then some reliance must be placed on enforcement techniques that involve the use of racial statistics. ${ }^{66}$ There are, however, no departures from the traditional understanding of racial discrimination. The employer is making some of his employment decisions on the basis of race. Some Negroes may be treated on the same basis as whites and obtain jobs; but the ones who are held to a higher standard than whites are being treated differently because of their race. The remedy is to prohibit this unequal treatment and to require that whatever criteria are applied to Negroes are also applied to whites in the same manner.

An exemption of a class of persons may also arise, not from "cheating" in its crudest sense, but from a change in standards. This results in an implicit exemption. The employer applies the new standards or criteria to all new applicants, both white and black, but does not apply it to those already working for him, and the race of this class is predominantly, if not exclusively, white. 67 This differs from "cheating" because the employer will admit the exemption and, more importantly, because the contours of the exempted class differ. In "cheating," the exempted class is "whites." With the implicit exemption, the exempted class is "those already hired." This latter class may consist of only whites but it is not coextensive with or reducible to the class "whites"

65 See, e.g., Griggs v. Duke Power Co., 420 F.2d 1225 (4th Cir.), cert. granted, 399 U.S. 926 (1970); Chambers v. Hendersonville County Bd. of Educ., 364 F.2d 189, 191 (4th Cir. 1966); EEOC Decision Case Nos. CC AT 7-2-112 (CC-7-2-554) to AT 68-7-99 E, June 30, 1969.

66 See text preceding note 44 supra.

67 See, e.g., Judge Sobeloff's analysis of the high school education requirement in Griggs v. Duke Power Co., 420 F.2d 1225, 1247 (4th Cir. 1970). See also Houston Maritime Ass'n v. NLRB, 168 N.L.R.B. 615 (1967) (freeze on all new applicants). 
because the criterion is applied to newly hired whites as well as to blacks.

The crux of the conceptual problem is that Negroes are treated in the same way as some whites but they are also treated differently from other whites. This raises the question whether the "significant" characteristic of those exempted is their race or the fact that they are already part of the work force. The Supreme Court faced this question in the voting context, and it concluded that race was the significant characteristic of the exempted class when it was established that Negroes had, because of their race, been excluded in the past from becoming members of the class now to be exempted. That was the general thrust of Guinn $v$. United States, the classic grandfather-clause case, and more clearly the result in United States $v$. Louisiana, where those already registered to vote were to be exempted from the application of a new literacy test. ${ }^{68}$ However, the courts are likely to move more cautiously in the employment context. Otherwise, too high a price would be placed on change. For example, even if it is established that the employer's present secretarial staff was not given the rigorous typing test now given to all new applicants and that, at the time the more lenient test was used, Negroes were denied jobs as typists because of their race, the courts are unlikely to condition the giving of the more rigorous typing test upon the retesting of all workers and the discharge of those who fail to satisfy it.

What justifies this caution in the employment context? First, the employer's interest in maximizing his own wealth and the regulatory power of the market make an employer's change of standard presumptively an effort to improve the productivity of his work force, not to disqualify all new applicants for employment. There is no such presumption in voting. There the new test was imposed by incumbent legislators who had everything to gain and little to lose by raising the qualifications even to the point of disenfranchising all new voterswhite and black. Second, the device used in voting to temper the ban on change of standards is, realistically speaking, unavailable in employment. In United States $v$. Louisiana the Supreme Court said it was permissible to use the new literacy test if there was a general re-registration; it merely prohibited its use until there was a general re-registration, that is, until it was applied to everyone. The Court no doubt knew that it was unlikely that the State would conduct such a re-registration; but the option was a real one, and it provided a ready response to the State's claim that the Court was precluding change. However, the option seems totally unrealistic in the employment context. The pros-

68 See note 64 supra. 
pect of subjecting all incumbent employees to the new standard at the risk of discharge has an adverse consequence upon the individual worker far greater than the risk of losing the right to vote under a general re-registration. However precious the right to vote is to democratic theory or for the legitimacy of government, holding a job is likely to be far more precious to the individual. In addition, from the employer's perspective the option of retesting makes little sense. Even if he changes his hiring standards on the view that they are better predictors of productivity than those used before, they are not likely to be better predictors than the work experience of incumbents. Third, one of the operative forces in voting was the inherent value of expanding the franchise-the view that it is a social good to increase the number of people that are allowed to vote. In employment, there may be a value in improving the economic status of Negroes, but once scarcity is acknowledged and the redistributive quality of that goal is perceived, an element of moderation not present in voting is introduced. Though the increase in the franchise might have the effect of diluting the votes of those already franchised, increasing the franchise of blacks does not take the vote from others.

Hence, though the implied exemption theory was the initial line for evaluating facially innocent criteria in the voting context, it is likely to play a lesser role in the employment context. Even if the court determines that Negroes were excluded (in the past) from the class now to be exempted from the facially innocent criteria, this should not be the end of the court's inquiry. A decree is not being sought against the past exclusion but against the present and seemingly evenhanded use of the facially innocent standard. Analytically, the issue is not whether there is past discrimination, or even whether that discrimination is being perpetuated, but whether the present use of the standard is discriminatory because of the exemption. That turns on what the court concludes to be the "significant" characteristic of the class-_"race" or "already hired"- -and that conclusion will reflect the outcome of the court's inquiry into the interests to be served by the changed standard. Save in the exceptional case, the court would conclude that a class is exempted, not because of the members' race (white) but because they are already employed, and thus there is little need for the employer to apply the new standard to them.

In those instances where the court concludes that the significant characteristic of the exempted class is race and turns to fashioning the remedy, there is a possibility that there will be a departure from the norm of color blindness. A racial distinction may be incorporated into the correctional scheme if the decree prohibits the application of the 
criterion to a class consisting primarily, if not entirely, of blacks. The underlying theory of such a remedy is to eliminate or neutralize the racial aspect of the class "those already hired" by affording those previously excluded because of their race the opportunity that they were previously denied-to be judged without regard to race and without regard to the criterion in question. Under such a remedial order the employer could apply the criterion to white applicants and some blacks, that is, those who were not excluded in the past, but for another group -all black-this criterion could not be applied. This remedy, conferring special benefits on a limited class of blacks, is analytically consistent with the antidiscrimination prohibition and the stricture against preferential treatment based on race: the benefits are not conferred on this class because they are black but, rather, because they are victims of the discrimination; and although the remedial order would improve the competitive position of the class, it would not give them a preference but put them on equal footing with those with whom they should be compared-those already hired.

Despite the permissibility of this color-conscious remedy, it is not likely to be used. Indeed, it was avoided in the most analogous voting case, United States $v$. Louisiana. The rejection of this remedy is in part due to the difficulty of identifying, with any degree of accuracy, the victims-the class or persons who should be relieved of the new test. The need for workable criteria - such as race, age, residence-for defining the class of victims and an appreciation of the ripple effect of any single discriminatory act would lead the court constantly to enlarge the class to be benefited by the decree beyond the narrow group of blacks who can establish that they were turned away at the company's door in the past because of their race. A significant over-inclusion of blacks would result if the concern were with benefiting the victims of past discrimination, and that is likely to lead to further over-inclusion-the dropping of the racial limitation altogether. As in United States $v$. Louisiana, the remedial order is likely to omit any racial distinction and, instead, prohibit the employer from using the new standard to judge any new applicants-white or black-who meet certain age and residence requirements. The employer may be able to get out from under such an order after a limited period of time, that is, after all the possible victims of past discrimination have had a reasonable time to take advantage of the court-created exemption; or he may be able to get out from under it by applying the standard to incumbents as well as new applicants. It should be emphasized, however, that this color-blind remedy of prohibiting the application of the new standard to a class of persons consisting of both whites and blacks exempts more persons from the 
standard than does an order under which all the beneficiaries are black; the employer himself may decide to exempt incumbent employees, but now he is ordered to exempt others. This increase in the size of the class of exempt persons under a color-blind remedy and a concern for the practical consequences of such an increase may be an additional factor leading the court to hesitate before finding an implied exemption for incumbent employees to be a violation of the antidiscrimination prohibition, even though the incumbent class is predominantly or exclusively white and that racial homogeneity is the result of past discriminatory practices.

b. The criterion itself: the theory of functional equivalence. There may be no issue as to the universe to which the criterion is applied; there may be a concession that it is applied to everyone in the same way. The question then is whether the reach of the antidiscrimination prohibition has been exhausted, and three factors may justify a second look at the criterion: evasion, unfair treatment, and the impact of the criterion on the equal-achievement goal.

The first factor-evasion-focuses on the ethical quality of the employer's conduct. The fear is that an employer will attempt to satisfy his taste for discrimination, or that of his workers or customers, by using a criterion which does not mention race but which accomplishes precisely the same result, namely, exclusion of Negroes from the work force. For example, if there is an all-white work force, the employer may use a nepotism criterion because it will produce the same result as if he used race.

Second, an attempt to reach the seemingly innocent criterion may be rooted in a concern for fair treatment of Negroes. It is thought just as unfair to judge a Negro on the basis of such a criterion as it is to judge him on the basis of race. This is particularly true with a nonmerit criterion, such as nepotism. Of course, it may be unfair to judge anyone, white or black, on the basis of such a criterion; but this does not lessen the unfairness when Negroes are judged by such a criterion, and unfair treatment of Negroes is viewed as particularly relevant considering the aims of fair employment laws.

A third source of concern relates to the goal of improving the relative economic position of blacks. If employers are allowed to apply facially innocent criteria with impunity, and if the consequence or effect of using these criteria is to limit the employment opportunities of Negroes or put them at a competitive disadvantage, the relative economic position of Negroes will not be improved. Inequalities in the actual distribution of jobs will persist. This concern assumes that the criterion in question limits or is likely to limit the employment opportunities of 
Negroes to a greater extent than it does those of whites, and in that sense will have a differential impact upon the two racial classes.

Regardless of the source of the concern, in each instance there is a stubborn analytic problem: how can an employment decision based on the individual's nonperformance under a facially innocent criterion be deemed to be an employment decision based on the individual's race? A desire to evade is not sufficient to establish a violation; it still remains to be determined that the employer chose his employees on the basis of race. Moreover, fair employment laws are not general guarantees of fair treatment to Negroes. Instead, the antidiscrimination prohibition forbids only one type of unfair treatment-discrimination against an individual on the basis of his race or color. And even if the aim of fair employment laws be redistribution, clearly this redistributive goal is not to be pursued without restraint. The obligation not to discriminate on the basis of race is the regulatory device for pursuing the redistributive goal, and the language and structure of that regulatory device cannot be ignored. The language and structure of the prohibition have been critical in formulating a general theory for fair employment laws and in establishing that employers and enforcement agencies can depart from the norm of color blindness and yet remain within the limits of the law.

One approach to the analytic problem emphasizes the employer's motive for choosing the criterion. The central causal concepts of the antidiscrimination prohibition, such as "based on," "because of," and "on the grounds of," are given a psychological gloss. They are thought to refer to the employer's state of mind. The theory is that if the employer chose the seemingly innocent criterion not to further his business interests but merely to satisfy his taste for discrimination (or that of his customers or workers), then the employment decision adversely affecting Negroes is not based on the innocent criterion but instead on race. Race is the "real" basis of the job allocation.

Perhaps, as a matter of semantics, it is possible to give the causal concepts such a psychological gloss. Even so, there are problems with this approach. One set of problems stems from the difficulties of proof. It is not just a question of the plaintiff's capacity to prove (or if the burden shifts, the defendant's capacity to disprove) a state of mind, but, more importantly, a question of what degree of confidence can be placed on a court's finding on the motivation issue. These questions are of some moment because a facially innocent criterion, by its very nature, always permits an assertion that it was chosen for legitimate business reasons, unrelated to a desire to exclude blacks. It is true even of the familiar nepotism example; for nepotism may be used to inculcate 
employee loyalty and to serve as a rough, but effective, screening device, somewhat like a voucher.

Another set of problems stems from the failure of the psychological approach to deal adequately with the situation where the employer's choice of criteria is based on motivation related to efficiency or to a mixed motive-race and efficiency. In these instances, the court may be able to make an independent assessment of the employer's alleged nonracial reasons for his choice and find that these reasons are not "suffcient," leading to the conclusion that only a desire to exclude blacks could "rationally" or "objectively" explain the use of the criterion. But . it is hardly a solution to the analytic problem to give the causal terms a psychological gloss and then "presume" as a matter of law that whenever, in the court's judgment, the use of the criteria cannot be justified on efficiency grounds, the "motivation" of the employer was a racial one. The bootstrap quality of that reasoning is apparent. Although the problems of proof stemming from the psychological approach may indeed be difficult, the franker solution is not to create "legal presumptions" about motivation but is, instead, not to give a psychological gloss to the causal terms of the prohibition.

Finally, and perhaps most importantly, the psychological approach is inadequate because it incorrectly conceives the nature of the regulatory device. Antidiscrimination prohibitions try to regulate by prohibiting the use of a criterion (race), and generally a violation of the prohibition does not turn on the motives or reason for the choice of the criterion. For example, when an election official turns blacks away, his motivation is irrelevant. It does not make a difference whether blacks are turned away at the polling place because the voting official hates blacks (is "prejudiced" or has a "racial animus") or just wants to help a particular candidate, white or black, whom the blacks are likely to vote against (has a purely political motivation). Regardless of his particular motivation, the official has violated the prohibition against racial discrimination by deciding who is to be turned away on the basis of the individual's color. The same is true in the employment context when race is the criterion in question. The employer violates the prohibition when he judges people on the basis of race, regardless of whether the employer chose that particular criterion, in whole or in part, because he wants to save the administrative costs of screening applicants (and uses race as symptomatic of poor education), because he hates blacks (and wants to screen out as many as possible), or because he wants to please his customers or his workers (who simply wish to maximize their wealth by limiting the supply of labor or preserving their competitive edge). The conduct that is regulated is the use of the criterion-judging people on 
the basis of the criterion-and the reasons or motives for the choice of the criterion are irrelevant under the theory and structure of fair employment laws. If that structure were for some reason altered in order to deal with the problem of facially innocent criteria, a series of discordant problems would be presented.

Another approach to this analytic problem, and one that seems more satisfactory, focuses on the criterion itself. The theory is that the seemingly innocent criterion is the functional equivalent of "race." Judging the individual on the basis of this criterion is the equivalent, or near equivalent, of judging him on the basis of race. There are two steps necessary to establish functional equivalence. The first is a determination that the criterion, like race, has or is likely to have an adverse differential impact on Negroes: the use of the criterion is more likely to limit the employment opportunities of Negroes as a class than those of whites. This first step essentially involves an empirical judgment about the actual or likely consequences or effects of applying the seemingly innocent criterion. The second step is considerably more difficult. It is to drain nonperformance under the criterion of any normative power: failure to satisfy the particular criterion could no more justify the adverse employment decision than could "race." This second step requires that the two attributes of race that make it an inappropriate basis for allocating jobs-unrelatedness to productivity and absence of individual control-also be attributes of the criterion in question. However, this can be done only through analysis of particular applications of the criterion; to consider a criterion innocent on its face is to concede that, unlike race, it is impossible to assert that there would be unfairness whenever that criterion is used as a basis for allocating jobs.

Admittedly, this approach takes some liberties with the word "race;" the law does not prohibit judging an individual on the basis of the functional equivalent of race but only on race. The virtue of this approach as a means for overcoming the analytic problem, assuming it should be overcome, is its consistency with the theory and structure of a fair employment law as a regulatory device. It focuses attention on the criterion, or basis of the employment decision, and avoids the difficulties of the psychological approach; if the criterion is the functional equivalent of race, there need not be a finding of the motivation of the employer in choosing the criterion.

This is not to deny that an inquiry into the employer's motivation might be relevant. ${ }^{69}$ For example, it may assist the court in determining

69 See, e.g., Insulators \& Asbestos Workers Local 53 v. Vogler, 407 F.2d 1047, 1054 (5th Cir. 1969). 
how blameworthy the employer's conduct is. A tribunal is likely to be hesitant in holding that an employer has violated any law, even if the relief in question is totally prospective, without some belief in the blameworthiness of the employer's conduct. When race itself is the criterion, the notice provided by the terms of the antidiscrimination prohibition will be sufficient to establish the blameworthiness of the employer's conduct. Here an inquiry into motivations-the bona fides of the employer-might serve the same function.

Similarly, an insight into the employer's state of mind may assist the court in determining functional equivalence. If the motivation seems to be connected to a "racial animus," the court is more prepared to second-guess the primary decision-maker on his choice of criteria. Thus it seems that whenever the Supreme Court has applied the theory of functional discrimination (for example, to invalidate literacy tests as a qualification for voting) it was well aware that the use of the criterion originated in the most suspicious of circumstances, suggesting that the motivation for the use of the criterion was a racial one (to disenfranchise blacks as a means of maintaining their inferior position). ${ }^{70}$ There was no doctrinal requirement that there be a racial motivation, and in some instances not even an explicit speculation as to the likely motivation. But the presence and significance of the surrounding circumstances could scarcely have been ignored, and surely they had an impact.

Even assuming that the theory of functional equivalence "overcomes" the analytic problem in a manner consistent with the structure of the antidiscrimination prohibition, the question of the role it should play in the enforcement of the law remains. Part of the answer to that question depends on the importance attached to such values as improving the relative economic position of blacks, insuring fair treatment in employment decisions, and preventing evasion. For example, the stronger the commitment to the value of improving the relative economic position of blacks (the equal-achievement goal), the rougher the approximation one will accept in establishing the equivalence. Indeed, that commitment may lead one even to forget the analytic problem altogether. ${ }^{71}$ However, the role of the functional equivalence

70 For example, the literacy test at issue in Gaston County v. United States, 395 U.S. 285 (1969), originated with a grandfather clause. See Fiss, Gaston County $v$. United States: Fruition of the Freezing Principle, supra note 2, at 386 n.23, 408.

71 See, e.g., Cooper \& Sobol, supra note 7, at 1600; Comment, supra note 7. The theory of functional equivalence might also be responsive to the problems posed by the fact that the major federal fair employment law-Title VII of the Civil Rights Act of 1964-did not become effective until July 2, 1965. (Elsewhere the theory might be responsive to statutes of limitations.) Without such a theory it would have been difficult or impossible to reach the clear discriminatory employment practices occurring before the effective date of the law, and that are perpetuated by the use-after the effective date-of such criteria as 
theory in enforcing fair employment laws may also turn on an awareness of certain conceptual and evidentiary difficulties in applying the theory-in establishing that a facially innocent criterion is the equivalent of race and determining the appropriate remedy once that equivalence is established. These difficulties may be of no moment with a criterion such as nepotism, but they are considerable when criteria such as seniority and testing are at issue.

Establishing the Functional Equivalence. In order to establish a functional equivalence, it might be determined that the criterion, like race, is unrelated to productivity. Nepotism and seniority do not appear to be accurate predictors of productivity. ${ }^{72}$ The more difficult determination involves criteria expressly designed to predict productivity, such as standardized tests. One difficulty involved in evaluating such criteria stems from the fact that the concept of predictiveness is a relative one. The question raised by such a seemingly innocent criterion is not whether nonperformance is predictive vel non but rather how predictive. The theory is that it is almost as poor a predictor as race, but there is no absolute or a priori measure of a "poor" predictor. A further complication arises because the relation of a criterion to productivity is not simply a function of its accuracy as a predictor. ${ }^{73}$ It may pay to use a poor predictor if the costs of administering or developing alternative predictors would exceed the value of the increase in productivity that would result from an increase in the accuracy of the predictor. Thus,

seniority and nepotism. This cannot ordinarily explain a concern with the use of other facially innocent criteria, such as aptitude tests or high school graduation. Morcover, some question can be raised about the propriety of the concern with pre-effective date employment practices, even if it is assumed that they are discriminatory; and, in any event, this concern seems to be transitory. It has been pronounced during the five years immediately following the effective date of Title VII, but it is likely to wane in the future.

72 To the extent that seniority measures experience, it has an ability-testing function. This ability-testing function can sometimes be separately identified, as for example, when the employer uses two criteria couched in terms of experience. An example is where a building trades union uses two seniority criteria for determining priority for referralsexperience in the industry and experience under the collective agreement. See, e.g., United States v. Sheet Metal Workers Local 36, 416 F.2d 123 (8th Cir. 1969); Dobbins v. Local 212, IBEW, 292 F. Supp. 413 (S.D. Ohio 1968). For an analysis of criteria explicitly designed to measure future performance, see Note, Legal Implications of the Use of Standardized Ability Tests in Employment and Education, 68 CoLUM. L. REv. 691 (1968); Cooper \& Sobol, supra note 7 , at 1637.

73 Cooper \& Sobol, supra note 7, at 1668, state their rule in the following terms:

The use of even a valid test should not be permitted where the test has a serious adverse impact on minorities and the party challenging the test can show there are available alternative devices with less adverse racial impact which seem to measure the same qualities with equal or greater validity.

As one gathers from this statement and the examples that follow, little account seems to be taken of the costs of validating tests or of the costs of administration of alternative techniques; and if it is possible to coerce a businessman to incur these costs, $I$ fail to see why he cannot be coerced to train the applicant for a typist job who does not quite come up to standards-a case they concede to be beyond the reach of the law. 
whether the criterion is conducive to productivity turns on four complex and interrelated judgments: (a) the accuracy of the predictor in question; (b) the accuracy that can be obtained by alternative means of predicting (either ones that are currently available or ones that can be developed); (c) the costs of developing better predictors; ${ }^{74}$ and (d) the costs of administering the alternative predictors. True, these factors were not considered in determining whether race was related to productivity; fair employment laws forbid the use of race even if the cost of imperfect prediction would be offset, for example, by the saving in administering the criterion. But several of the important reasons for that construction are not present when dealing with facially innocent criteria. The ban on the symptomatic use of race was in part based on a desire to avoid the complications and inefficiencies of excepting what is presumably an atypical use of race, and it is also based on the similarity in appearance of the symptomatic and wrongful uses of race. In the case of facially innocent criteria, there is neither the appearance nor much empirical base to assume that the employer is using a criterion that is unrelated to productivity. It is obviously in the employer's self-interest to insure that the criterion is conducive to productivity. There may be situations where the regulatory power of the market is inadequateperhaps the same situation that would prompt the wealth-maximizing employer to use race; yet it is impossible to assume that those situations could account for all or most uses of these productivity-oriented criteria.

Once it is established that the seemingly innocent criterion is almost as unrelated to productivity as race, there remains, of course, the task of determining whether the individual is responsible for his failure to satisfy the criterion. Lack of individual control is one of the attributes of race that accounts for the unfairness inherent in its use as a basis of allocating scarce employment opportunities. It should also be required to establish functional equivalence, unless the obligation of the antidiscrimination prohibition is reduced to a ban on the use of "poor" predictors that have a differential impact. The lack of individual control seems necessary to establish the unfairness in using the criterion; and for this purpose past discrimination against the racial class is

74 The costs of developing alternative predictors include personnel costs (e.g., persons to devise tests, administer the tests, and interview workers), and the costs of maintaining the necessary records. If the aim is to obtain a validated test, that is, one that accurately predicts performance for all groups, there will also be the risk of costs arising from the lessening of productivity; for the validation of a test involves assembling a representative sample of applicants, selecting the workers on a random basis, giving the test to all of the applicants selected on this random basis, putting them to work for some period of time, and then measuring their level of performance to determine what correlation, if any, exists between it and the test score. See Note, supra note 72, at 696. 
relevant. Past discrimination may have impaired the individuals' ability to satisfy the criteria and has put the victims at a competitive disadvantage as compared to whites. For example, discrimination in the public educational system or exclusion from company training programs may be the explanation for poor performance on a test. Or past discrimination may limit the capacity of blacks to meet criteria that do have an explicit reference to time, such as seniority rules. In either case, the court must attempt to reconstruct the past and, perhaps more importantly, must distinguish between the past wrongs that are an inevitable part of the socialization or development process and those that are of such unique, systematic character as to relieve the individual of responsibility for his nonperformance while holding most others responsible for their nonperformance.

Outside of the employment area, such as in voting, the unfairness of using a seemingly innocent criterion may be established if this lack of individual control, perhaps attributable to past discrimination, is established. The courts have spoken about the "perpetuation" of past discrimination. However, in the employment context, unrelatedness to productivity must also be established. Even assuming that the individual was never in a position to bring himself within the terms of the criterion, that it can be explained on the ground of past discrimination against his class, the law is not prepared to coerce the businessman to incur the costs involved in hiring the (admittedly) less productive worker or of training him so as to increase his productivity. The employer's interest in wealth maximization and the rigors of the marketplace are generally acknowledged in fair employment laws. A fair employment law is a limited corrective strategy and the societal interest in efficiency is a major limitation. This interest in efficiency is compromised not only when the employer is required to take an "unqualified" worker but also when he is not allowed to choose "the best worker." Thus, in the employment context, if the individual's nonperformance under the criterion indicates a lower productivity than that of another applicant (for example, the applicant for a secretarial job cannot type at all or cannot type as well as the best applicant), this criterion cannot be deemed the functional equivalent of race, regardless of the individual's lack of responsibility for his nonperformance. Past discrimination -the causal explanation that releases the individual from responsibility for his nonperformance-becomes relevant only if the criterion is not indicative of productivity. A limited exception may be made when the government is the employer and the costs are spread throughout society. Conceivably, another exception may be made when the employer himself is responsible for the imposition of the disability. For instance, the 
past discrimination may occur in the company training program, rather than in the public educational system. Then the law may be more prepared to coerce the employer to incur costs by providing training opportunities; he has the remedial obligation to correct the effects of his discrimination. But both of these instances seem marginal. The general obligation of the employer should be and has been formulated from a different perspective.

Fashioning the Remedy. Even if it is determined that the employer's use of a seemingly innocent criterion is the functional equivalent of using race, the problem of fashioning a remedy remains. Obviously, an order commanding the employer not to use race for allocating jobs is ill-suited to the task. What remedy, then, would be both effective and fair?

One possible remedial order is a flat ban on the use of the seemingly innocent criterion: the particular employer is ordered not to apply the criterion to anyone. This may be done with the nepotism rule or a requirement that the applicant have a high school diploma. The remedy appears evenhanded-whites and blacks will be treated alike. But, to a limited degree, that appearance is misleading. A benefit is conferred upon a group that consists primarily of blacks, and a disadvantage is imposed on a class that consists primarily of whites. This is so because a finding of functional equivalence necessarily implies that the use of the criterion has a differential impact on whites as a class and blacks as a class. Likewise, a flat ban on use of the criterion will have a differential impact on the two classes. The person who would otherwise be unable to meet the criterion receives a benefit; the person who could otherwise have satisfied the criterion is disadvantaged because his competitive edge is nullifled.

This conferral of benefit and disadvantage becomes of more significance in the employment context than in voting. Abolishing a literacy test as a qualification for voting confers benefits and disadvantages in much the same way as abolishing a requirement of high school graduation does in employment. But enfranchising an illiterate, though it may dilute the literate's vote, neither deprives the literate of the vote nor puts the illiterate in a position to deprive the literate of the vote. They are not in competition with one another. Each can vote. In employment, a scarce opportunity must be allocated: the job that goes to one cannot go to the other (although the unsuccessful applicant may not be deprived of all employment). However, if functional equivalence between race and the criterion is established, the stricture against preferential treatment based on race would not be violated: prohibiting the use of this criterion confers a benefit that is identical to the benefit conferred 
by prohibiting the use of race. The antidiscrimination prohibitioneven in its color-blind version-improves the competitive position of blacks.

A flat ban on the use of a criterion has the appearance of evenhandedness, but often it is not an appropriate or a practical remedy. This may be due to political considerations. For example, the use of seniority, even if found to be nonconducive to productivity and even if the nonperformance of blacks under the criterion is attributable to past discrimination, is not likely to be totally prohibited. The impact upon the incumbent workers, mostly white but including some blacks, would be too great, and that constituency can make its power felt in ways that would preclude or undo any flat ban on the use of seniority. Or the remedial alternative of a ban may be unavailable because of considerations of economic efficiency. For example, the written test in question may be a poor predictor, but it is the only one available in the immediate future. Banning it may decrease productivity or, because of the costs of developing new validated tests, prompt an increase in the price of goods and services. Indeed, if a decree prohibits the use of the criterion altogether and an increasing number of facially innocent criteria come within the sweep of such decrees, the risk that employers will use the not so innocent criterion-race-increases. Some employers may use this to the advantage of blacks; others may use it to the advantage of whites.

Thus, what is often necessary is a more tailored decree-one that permits use of the criterion but tries to remove the discrimination. The process of formulating the tailored decree involves two critical phases: delineating the class of beneficiaries and equalizing the effect of the criterion on this class of beneficiaries.

Theoretically, the defining characteristic of the class of beneficiaries is that they are victims of discrimination; and, as with the traditional theory of fair employment laws, it is not troubling that the race of the class turns out to be black. However, as a practical matter, race is likely to play a large role in defining the class of beneficiaries, and the racial composition of the benefited class is more than a mere coincidence. In the testing situation, for example, it would practically be impossible to define in advance and in nonracial terms those victims of discrimination whose scores must be adjusted in order to neutralize the influence of past discrimination in the public educational system. Instead, the color black is likely to be used symptomatically to identify "victims of discrimination"; the class of beneficiaries becomes coextensive with the color black. At most, there is an insincere promise to exclude the nondisadvantaged black from the benefit of the decree wherever he is found. 
The same symptomatic use of the color black and the expansion of the class of beneficiaries seem inevitable when the criterion is seniority and the question is who should not be disadvantaged because they have not accumulated as much seniority as whites. For the all-white company, which has never hired blacks, race plays a predominant role, although there may be further delineation of the class in terms of age and residence. The theory is that to hold individuals, who were denied the opportunity to work in the plant because of their race, to the same seniority standards as whites would be to discriminate against them on the basis of their race. A delineation of the class of beneficiaries in terms of those blacks who actually applied to the company in the past but were turned away because of their race would seem too limited: the evidentiary problems of identifying those individuals would be enormous, and this limitation of the class would not take sufficient account of the ripple effect of discriminatory action and of discouragement through images. Where there are racially segregated departments, and the challenge is to the use of seniority in the white department, a delineation of the beneficiaries in terms of incumbent black employees is likely. On one level, this delineation is over-inclusive because it benefits those who would not have been admitted to the white department regardless of racial considerations. On another level, it is under-inclusive. It fails to include those blacks who were not hired because of limitations on the number of job openings in the black department there and those who would not even apply because of the discriminatory practices. It may, of course, be difficult to identify these individual victims, and this creates pressure to expand the class of beneficiaries beyond the incumbent black employees to include blacks in the community who satisfy certain age and residence requirements. If the class of beneficiaries is not so expanded, the remedial order, and thus the resources consumed in the litigation, would do no more than improve the position of a limited number of older blacks who were prepared to serve in the segregated black department over a long number of years.

Once the class of beneficiaries is delineated, the decree must neutralize the discriminatory effect of the criterion. Assuming a situation where the use of the criterion is still permitted, "credit" must be given to the class of beneficiaries to offset their nonperformance. This credit could be conferred "explicitly." For example, some number of points would be added to the test score of the beneficiaries or some quantity of seniority given to offset the nonaccumulation. Credit could also be given to the beneficiaries indirectly by lowering the standards by which they are judged-by creating a double standard. Or credit could be given indirectly by downgrading or devaluating the performance of 
those outside the class of beneficiaries; for example, the tribunal could order the employer to limit the amount of seniority an employee outside of the class of beneficiaries could use for competitive purposes. In formulating an order that does not prohibit the use of the criterion altogether, the central question is: how much credit should be given to the class of beneficiaries?

The answer is easy enough when stated in general terms; enough credit should be given that the beneficiaries are assured equal treatment or their "rightful" place. ${ }^{75}$ But it is extraordinarily difficult to give specific content to such a tautological answer. The task confronting the tribunal is not to devise a formula to give the job to the class of beneficiaries or to eliminate the differential impact of the criterion-to make the test scores or accumulated seniority quantitatively identical. Instead, the task is to eliminate only that portion of the differential impact attributable to past discrimination. At that point the functional equivalence between the seemingly innocent criterion and race ceases, and so does the justification for giving any credit. And the difficulty of locating that point with any degree of accuracy is obvious. How many points should be added to the test score of the beneficiaries to cancel the effects of past discrimination in the educational system? How much time will account for the loss of accumulated time attributable to the past exclusionary practices of the company or industry? In the seniority case where there are racially segregated departments and the remedy is limited to incumbent blacks who wish to compete, there may be some rough approximations, such as company seniority. But obviously the approximation is very rough, for it rests on the unrealistic assumption that, without the past practices, the incumbent blacks (the beneficiaries) would have started work in the white department at the same time as they did in the black one and would have continued in the white department in the same fashion as they did in the black one.

These difficulties in computing the appropriate credit are of some moment. They not only make the remedial enterprise more complicated but they also create a risk of transforming the remedial order into a mechanism for securing not equal but preferential treatment for the class of beneficiaries. The tailored decree avoids a conflict with the stricture against preferential treatment based on race if it observes two linitations. The first is that, even though the class of beneficiaries may be predominantly, if not exclusively, blacks, the benefits are not being conferred because of their race but because they are victims of discrimination. Race is used to identify beneficiaries, but it is being used

75 See generally Note, Title VII, Seniority Discrimination and the Incumbent Negro, 80 Harv. L. REv. 1260 (1967). 
symptomatically, along with some other criteria, to identify the victims. Benefits are not conferred on these individuals because of race, but (in much the same way as any version of the fair employment law works) because there is no way, in the immediate future, to end the discrimination other than by requiring action (giving credit) that entails conferring benefits. The second limitation is that the benefit conferred is limited. It will result only in the applicant being treated equally. So long as the credit does no more than neutralize the discriminatory effect of the criterion, the claim can be made that, notwithstanding the outward appearance of unequal treatment (the additional credit), the beneficiaries are merely treated equally and thus the remedy is consistent with the theory of a fair employment law. The familiar analogy is the handicap race. However, just as too small a handicap leaves the discrimination uncorrected, too great a handicap gives an unjustifiable advantage-not equal but preferential treatment. Obviously those competitors without the handicap are unlikely to accept someone else's assurance that not too much has been given, and the protestations cannot be lightly dismissed as assertions of limited self-interest when there are such enormous difficulties in doing the job correctly. ${ }^{78}$

The difficulties in identifying the class of beneficiaries and in computing the appropriate credit parallel the difficulties inherent in determining that the prohibition was violated. In that regard there were difficulties in determining whether the criterion is related to productivity and the individual's responsibility for his nonperformance, assessments which are necessary to conclude that a seemingly innocent criterion is the functional equivalent of race. These difficulties, both in fashioning the remedy and in concluding that there is an equivalence, make the process of evaluating facially innocent criteria a costly one. One facet of the costs is ethical: at each step of the analysis, the tribunal is called upon to make treacherous decisions about individual responsibility and competitive fairness. The risk of error is high, and there is little chance of agreement as to the correctness of those judgments. In addition, this process of evaluation consumes significant economic resources. My concern does not relate simply to the resources consumed by a protracted adjudicatory process, or to the inefficiencies that could

76 This is clearly illustrated in Papermakers \& Paperworkers Local 189 v. United States, 416 F.2d 980 (5th Gir. 1969), where, at various points of time, three different public agencies charged with enforcing an antidiscrimination prohibition-the Equal Employment Opportunity Commission, the Office of Federal Contract Compliance, and the Department of Justice-had taken quite different views as to the amount of seniority "credit" that had to be given to incumbent black employees, and none of these agencies, nor the court, was prepared to extend the class of beneficiaries to embrace nonincumbent blacks, that is, blacks who had not remained at the company but who nonetheless might have been the victims of the past discriminatory practices of the employer. 
be imposed on the good businessman through a mistaken adjudication, thereby increasing the costs of goods and services. Instead, my concern stems primarily from the unlikelihood of any real payoff from the investment. It is unlikely that the results of any single litigation could be generalized or become the basis of any significant measure of voluntary compliance. As we have seen, one aspect of the theory of fair employment laws was that the costs of enforcement could be kept down through voluntary compliance; all employers knew that race was forbidden and could act accordingly. In this important regard, no facially innocent criterion will ever be the general equivalent of race: it is impossible to formulate a legal prohibition against the use of the criterion in the same way that fair employment laws embody a prohibition against race. The legality of a criterion depends on many complicated facts, such as those necessary to make a determination that it has an adverse impact, that it is not conducive to productivity, and that the individual is not responsible for nonperformance. These facts vary from case to case, with only a limited potential for developing per se rules. With the criteria that really count, not nepotism but testing and seniority, there is no single or typical set of facts that would allow the tribunal to generalize the rule to cover all employment decisions within the reach of the fair employment law. The litigation in voting culminated in a nationwide ban on literacy tests; ${ }^{77}$ but it is impossible to contemplate that outcome in employment-at least today.

It is these considerations, not the obvious departure from the norm of color blindness, that raise doubts about the wisdom of the evaluative process related to facially innocent criteria admittedly applied to everyone in the same way. These costs may not be sufficient to cause the courts to shrink altogether from this type of evaluation; the courts have embarked on the enterprise, and there may be good practical reasons for continuing. These reasons stem from the risks of the alternative posture, that is, one where facially innocent criteria are immune to or insulated from attack under the fair employment law. This second posture would enable those who wish to satisfy a taste for discrimination to do so in an indirect fashion, and it may well have disastrous effects on the achievement of the aggregate economic goal-that of improving the relative economic position of Negroes. The blanket legitimation of facially innocent criteria might well result in the perpetuation of the inferior economic position of blacks and thus frustrate one possible aim of fair employment laws.

These pragmatic reasons suggest a purpose for continuing the enter-

77 Title II of Voting Rights Act Amendments of 1970, Pub. L. 91-285, 84 Stat. 314; United States v. Arizona, 91 S. Ct. 260 (1970). 
prise of evaluating facially innocent criteria. But they are not sufficient reason for mounting a massive indiscriminate enforcement program. The difficulties inherent in making the judgments and the individualized nature of any conclusion of functional equivalence suggest that the rational law enforcement policy is to save this analysis for exceptional cases. Those are likely to arise where the merit principle is not able to protect itself; a prime example is the criteria used to establish priorities in a union-controlled referral system, such as in the building trades industry. A properly selective use of the theory of functional equivalence would preclude the wholesale legitimation of all facially innocent criteria and keep some pressure on employers to develop criteria that are not near-cousins of race. At the same time it would minimize the societal costs involved in using this theory.

3. The Affirmative-Action Duty. My formulation of a theory of fair employment laws and the analysis of the departures from color blindness have been based on an idealized version of a fair employment law, a prototype abstracted from any particular setting. It consists of nothing more than a command to employers not to discriminate on the basis of race or color. That seems to be the central regulatory device of laws prohibiting racial discrimination. There is, however, one phrase in both Title VII of the Civil Rights Act of 1964 and the Executive Order that has become an important appendage to the central regulatory device. That is the phrase "affirmative action." It has recently been used with greater frequency. ${ }^{78}$ And it no longer remains just a detail of language. Instead, it has given rise to a duty-the affirmative-action duty.

The affirmative-action duty does not purport to supplant the duty not to discriminate, nor could it be understood independently of the duty not to discriminate. The assumption is that the employer's basic duty is not to discriminate and the affirmative-action duty is just "one step" beyond that. In the typical scenario, the enforcement agency tells the employer that he not only must refrain from discrimination but also must undertake "affirmative action." The employer asks what "affirmative action" is: "What is it I have to do?" The response of the enforcement agency is essentially one of silence. It says: "Just as you use your ingenuity in solving other business problems, you should use your ingenuity in solving this one." The most the agency is willing to do is to provide a few clues as to what "affirmative action" might entail. The agency mentions an aggressive informational program for blacks as one

78 See, e.g., United States v. Local 38, IBEW, 428 F.2d 144 (6th Cir. 1970); Insulators \& Asbestos Workers Local 53 v. Vogler, 407 F.2d 1047 (5th Cir. 1969); Weiner v. Cuyahoga Community College Dist., 19 Ohio St. 2d 35, 249 N.E.2d 907 (1969). 
example. It then quickly adds that this example is not meant to exhaust the employer's affirmative-action obligation.

There are several possible explanations for the agency's failure to explain what the affirmative-action duty entails. The first is that the agency does not know. The phrase "affirmative action" is unintelligible to the agency. In that instance the use of the phrase is obviously inexcusable. I do not believe that effective law enforcement results from, or is in any way furthered by, using concepts the meaning of which is not clear to either speaker or listener.

A second explanation for the silence is that the term "affirmative action" has no descriptive meaning but is used simply as an exhortation. It means "Think right." It is the agency's way of urging the employer to be more concerned with the problem of racial discrimination. I see little place for exhortations in law enforcement. The necessity for enforcement action itself suggests that the employer is not "thinking right," not sufficiently concerned with discrimination, and a simple exhortation is unlikely to cause a change. What is necessary for law enforcement that is both effective and efficient-free of interminable negotiations or motions for supplemental relief-is clarity and specificity, not exhortations.

A third explanation for the silence is embarrassment. Although the term may have descriptive meaning and although the agency may know that meaning, the agency is embarrassed to say what it means. This embarrassment is, of course, not attributable to social graces; it is more likely attributable to fear of the political consequences of informing the employer precisely what is expected of him or to the uncertainty on the part of the agency as to the legality of the action it wants the employer to take. The agency wants the employer to do anything that is necessary to increase the number of black workers or to improve the relative economic position of Negroes. Of course, one means of doing that is to give blacks a preference because of their color. In this instance, the phrase "affirmative action" is a technique for avoiding the political or legal consequences of the agency's directive.

If this is the explanation for its silence, the agency is acting irresponsibly. An agency's accountability would be completely undermined if it could obscure its directives and enforcement policies by steadfastly refusing to explain the meaning of a term that plays a central role in those directives and policies. Moreover, there is no suggestion that the "affirmative action" concept, as it appears in the laws in question, means that the obligation of the employer is to increase the number of blacks employed. In Title VII its meaning is purely remedial. ${ }^{79}$

79 Section $706(\mathrm{~g})$ provides: "If the court finds that the respondent has intentionally 
It means that, once the tribunal has found that the employer has discriminated, the court may order the employer to engage in action to correct the effects of the discrimination, even if this action may be considered "affirmative" and not otherwise specifically authorized by the statute. Reinstatement and hiring, with or without the payment of back wages, are the statutory examples. The suggestion is that the corrective action ordered by the court need not be specifically authorized or required by the antidiscrimination prohibition in itself. However, there is no suggestion that the remedial obligation of the employer-even if it is established that he has discriminated-is simply to increase the number of blacks, and much less that that goal could be achieved in ways that transgress the basic prohibition of the statute.

This also seems to be true with the term "affirmative action" as used in the Executive Order. ${ }^{80}$ In that instance it seems to mean that the government contractor may be required to incur greater expenses or inefficiencies to help insure against racial discrimination-a policy that may be justified on the assumption that the increased costs will be borne by the government and spread throughout society. ${ }^{81}$ There is no suggestion that the basic obligation of the government contractor is to increase the number of blacks hired and no suggestion that he is permitted or obliged to allocate scarce employment opportunities on the basis of color for the purpose of fulfilling that obligation. If that were the obligation of the Executive Order, there would be a conflict with Title VII and a serious question about the constitutional authority of

engaged in or is intentionally engaging in an unlawful employment practice charged in the complaint, the court may enjoin the respondent from engaging in such unlawful employment practice, and order such affirmative action as may be appropriate, which may include reinstatement or hiring of employees, with or without back pay . . ." 42 U.S.C. $\$ 2000 \mathrm{e}-5(\mathrm{~g})$ (1964). Courts have granted analogous relief without specific statutory authorization, finding the power in general equity principles. See, e.g., United States v. Alabama, 192 F. Supp. 677 (M.D. Ala. 1961), aff'd, 304 F.2d 583 (5th Cir.), affd per curiam, 371 U.S. 37 (1962) (list of 54 Negroes to be registered to vote). See also cases cited in Fiss, Gaston County 0 . United States: Fruition of the Freezing Principle, supra note 2, at 396 n.47.

80 Executive Order 11,246 requires that all government contracting agencies include in every contract the following provision:

During the performance of this contract, the contractor agrees as follows:

(1) The contractor will not discriminate against any employee or applicant for employment because of race, color, religion, sex, or national origin. The contractor will take affirmative action to ensure that applicants are employed, and that employees are treated during employment, without regard to their race, color, religion, sex, or national origin. ...

3 C.F.R. 167 (1965), as amended Exec. Order No. 11,375, 3 G.F.R. 320 (1967), 42 U.S.C. $\S 2000$ e (Supp. 1II, 1965-67).

81 In Weiner v. Cuyahoga Community College Dist., 19 Ohio St. 2d 35, 38, 249 N.E.2d 907,910 (1969), the court suggests that the increased cost due to a requirement to undertake affirmative action might be offset by the avoidance of the costs attendant on traditional means of enforcing fair employment laws. 
the Executive to impose such obligations..$^{82}$ But there is no conflict. The basic obligation remains one of not discriminating, even though, when this obligation is scrupulously obeyed or pursued at some expense, the result or consequence may be an increase in the number of blacks. The government contractor promises to take "affirmative action to ensure that applicants are employed ... without regard to their race," and he also promises not to discriminate on the basis of race or color.

To argue for a short life for the affirmative-action duty and to suggest that it should not be the concept that supplants color blindness does not mean that a court cannot require the employer who has been found to discriminate to take what might be considered affirmative steps. Instead, I would suggest that the courts usually do precisely that, and that in the remedial area the distinction between affirmative and negative action is not a helpful one. Indeed, it has long been recognized that there is an inherent power of an equity court to require the defendant to take affirmative steps to undo or correct the effects of his wrongful conduct. ${ }^{83}$ To the extent that it is not redundant, the affirmative-action concept is either meaningless or inconsistent with the prohibition against discrimination. Most often it is used simply as a bluff.

\section{Conclusion}

The essential quality of the antidiscrimination prohibition as applied to employment decisions is not color blindness. In my judgment, there are two other qualities that are the key to understanding: first, that the antidiscrimination prohibition is a strategy for conferring benefits on a racial class-blacks-and, second, that as a benefit-conferring strategy it is limited. It does no more than prohibit discrimination on the basis of race. The limited nature of this legal strategy is not just a function of the circumstances of politics but rather reflects a deep commitment to the values of economic efficiency and individual fairness. The most troublesome question is whether the historical legacy of the class will, or should, moderate that commitment so as to yield, through enactment

82 Id. at 39. In his opinion on the legality of the Philadelphia Plan, the Attorney General takes the position that the affirmative action entails the duty to increase minority employment, but not in a manner that would conflict with Title VII. Senate Hearings on the Philadelphia Plan at 276-79. See note 49 supra.

83 See, e.g., Fiss, Racial Imbalance in the Public Schools: The Constitutional Concepts, supra note 2, at 612; United States v. Jefferson County Bd. of Educ., 372 F.2d 836, 868 (5th Cir. 1966), aff'd en banc, 380 F.2d 385 (1967); and Green v. County School Bd., 391 U.S. 490, 437-38 (1968), where the Court said: "School boards such as the respondent then operating state-compelled dual systems were nevertheless clearly charged with the affirmative duty to take whatever steps might be necessary to convert to a unitary system in which racial discrimination would be eliminated root and branch." See also Griffin v. County School Bd., 377 U.S. 218 (1964). 
or construction, a more robust strategy for the law. The legacy supplies an ethical basis for the desire to improve the relative economic position of blacks, and yet it also explains why a law that does no more than prohibit discrimination on the basis of race will leave that desire, in large part, unfulfilled. 